\title{
Alteraciones en la homeostasis del colesterol hepático y sus IMPLICACIONES EN LA ESTEATOHEPATITIS NO ALCOHÓLICA
}

\author{
Joel Vega-Badillo',2 \\ ${ }^{1}$ Programa de Doctorado en Ciencias Bioquímicas, Facultad de Química, Universidad \\ Nacional Autónoma de México (UNAM), Ciudad Universitaria, Deleg. Coyoacán, C.P. \\ 04510, Ciudad de México, México. Unidad de Genómica de Poblaciones Aplicada \\ a la Salud, Facultad de Química, UNAM/Instituto Nacional de Medicina Genómica \\ (INMEGEN), Periférico Sur No. 4809, Colonia Arenal Tepepan, Deleg. Tlalpan, C.P. \\ 14610, Ciudad de México, México. E-mail: badillo160682@hotmail.com
}

\begin{abstract}
Resumen
Diversos estudios han demostrado que el colesterol libre (CL) hepático tiene una participación importante en la patogénesis de la esteatohepatitis no alcohólica (EHNA). Estos estudios han proporcionado evidencias de que la acumulación en el hígado de CL es tóxico a distintos niveles incluyendo: daño oxidativo a la mitocondria, estrés del retículo endoplasmático (RE) y activación de células de Kupffer (CKs) y células estelares hepáticas (CEH). En conjunto, estas evidencias sugieren que el contenido de CL hepático es importante en el inicio, mantenimiento y modulación de la respuesta inflamatoria asociada a la EHNA. En esta revisión, se discuten los distintos mecanismos participantes en la regulación de la homeostasis del colesterol y sus posibles implicaciones en el desarrollo y progresión del hígado graso no alcohólico (HGNA).
\end{abstract}

Palabras Clave: colesterol libre, EHNA, fibrosis, HGNA, homeostasis.

\section{Dysregulation in hepatic cholesterol homeostasis and its implications in nonalcoholic steatohepatitis}

\begin{abstract}
Several studies have shown that hepatic free cholesterol (FC) has an important role in the pathogenesis of nonalcoholic steatohepatitis (NASH). These studies have provided evidence that hepatic FC accumulation is toxic at different levels including: mitochondrial oxidative injury, endoplasmic reticulum (ER) stress, and activation of Kupffer cells (KCs) and hepatic stellate cell (HSCs). Altogether, this suggests that hepatic FC content is important for the initiation, maintenance and modulation of the inflammatory response associated with NASH. In this review several mechanisms that participate in the regulation of cholesterol homeostasis and their possible implications in the development and progression of nonalcoholic fatty liver disease (NAFLD) are discussed.
\end{abstract}

Key Words: free cholesterol, NASH, fibrosis, NAFLD, homeostasis. 


\section{INTRODUCCIÓN}

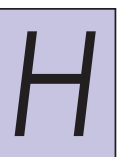

\section{ígado graso no alcohólico (HGNA)}

El hígado graso no alcohólico (HGNA) es la enfermedad hepática crónica más común, sin una historia de consumo significativo de alcohol. Esta patología está frecuentemente asociada con la presencia de obesidad, resistencia a la insulina y otras características del síndrome metabólico ${ }^{1,2}$. El HGNA se caracteriza por la acumulación de grasa en los hepatocitos que excede el 5\% del peso del hígado 3 . El fenotipo histológico del HGNA se extiende desde grasa en el hígado (esteatosis simple, ES) hasta esteatohepatitis no alcohólica (EHNA) ${ }^{4}$. Esta última caracterizada por la presencia de esteatosis, inflamación lobular, balonamiento hepatocelular y diferentes grados de fibrosis, con un alto riesgo de desarrollar otras complicaciones como cirrosis y carcinoma hepatocelular ${ }^{3,4}$. Se ha establecido claramente que la obesidad central, la diabetes tipo 2 (DT2) y la resistencia a la insulina son factores de riesgo para el desarrollo de esteatosis hepática ${ }^{5}$. Sin embargo, los factores y mecanismos moleculares responsables para el desarrollo de inflamación en la progresión a EHNA, aún no han sido completamente dilucidados ${ }^{6,7}$. Se desconoce por qué algunos pacientes con HGNA permanecen con $\mathrm{ES}$ benigna, mientras que otros progresan a EHNA y fibrosis.

\section{Prevalencia del HGNA}

De manera reciente, un estudio a nivel global encontró que el $25 \%$ de la población adulta en el mundo presenta HGNA ${ }^{8}$. Además, se estima que hasta un $30 \%$ de los sujetos con HGNA progresan a EHNA ${ }^{9}$. Es por ello que desde el año 2004, el número de adultos con complicaciones derivadas de EHNA, en espera de trasplante hepático (TH), casi se ha triplicado en los EUA, siendo actualmente la EHNA la segunda indicación más común para trasplante hepático, sólo después de la enfermedad hepática causada por el virus de la hepatitis C (VHC). Pero se estima que en los siguientes 10 a 20 años, las complicaciones por EHNA serán la primera causa de trasplante hepático ${ }^{10-12}$.

\section{Patogénesis del HGNA}

La hipótesis más aceptada para entender la patogénesis del HGNA es la propuesta por Day y James $(1998)^{13}$, que consiste en dos agresiones, la primera de ellas para el establecimiento de la esteatosis hepática, debido a la acumulación de ácidos grasos (AGs) y triglicéridos, como consecuencia del incremento en la captación y/o síntesis de AGs, así como la disminución de la beta oxidación de los mismos. La progresión de esteatosis a EHNA se establece a través de una segunda agresión, que parte de un hígado esteatótico más vulnerable al daño hepatocelular e inflamación. Los principales mecanismos involucrados en la segunda agresión incluyen al estrés oxidante, disfunción mitocondrial e inmunomodulación a través de distintas citocinas. Sin embargo, aun cuando esta hipótesis es ampliamente aceptada, estudios recientes sugieren que la progresión a EHNA ocurre en un proceso continuo, donde los lípidos con capacidad tóxica/ pro-inflamatoria promueven un efecto de lipotoxicidad, lo cual conlleva a la progresión de esteatosis a EHNA ${ }^{14}$. A este respecto, distintas investigaciones se han enfocado en determinar la participación de diversos tipos de lípidos en la progresión a EHNA. Por ejemplo, aun cuando el HGNA se asocia con el incremento de triglicéridos hepáticos ${ }^{15}$, datos experimentales en modelos murinos con EHNA, en los cuales la síntesis de triglicéridos y la esteatosis hepática fue inhibida, el daño y la fibrosis hepática incrementó considerablemente ${ }^{16}$. Asimismo, pacientes con hipobetalipoproteinemia familiar (HBF) no progresaron a cirrosis a pesar de la presencia de esteatosis masiva $^{17}$, lo que sugiere que la acumulación de triglicéridos per se podría no ser un factor determinante para la progresión. En este sentido, la investigación se ha enfocado en el estudio de otros lípidos como: ácidos grasos libres (AGL), diacilgliceroles, fosfolípidos (ceramidas y esfingolípidos) y más recientemente colesterol libre $(\mathrm{CL})^{14}$. A este respecto, dos estudios a nivel lipidómico sugieren que son los niveles hepáticos de CL y no los triglicéridos, los que se encuentran diferencialmente elevados en los sujetos que progresan a EHNA ${ }^{18,19}$.

\section{Función biológica del colesterol}

El colesterol (3-hidroxi-5,6 colesteno) es un esterol (lípido) indispensable para la vida, desempeña funciones estructurales y metabólicas que son vitales para el ser humano ${ }^{20}$. Esta molécula se encuentra anclada estratégicamente en las membranas, donde modula la fluidez, permeabilidad y en consecuencia su función ${ }^{20}$. Constituye el elemento estructural básico del esqueleto de las membranas celulares ${ }^{21}$. Sin su refuerzo las membranas serían extremadamente fluidas y perderían su consistencia ${ }^{21}$. El colesterol también modula las funciones de las proteínas membranales y participa en varios procesos de tráfico y señalización transmembranal ${ }^{22}$. Además, es precursor de biomoléculas fisiológicamente importantes como las hormonas esteroideas, ácidos biliares y vitamina $\mathrm{D}^{20}$.

\section{Síntesis, regulación y transporte del colesterol}

Para el aporte de colesterol corporal, la contribución de la síntesis de colesterol de novo en comparación con la ingesta dietética se estima en una proporción de $\sim 70: 30^{22,23}$. En la práctica, esto probablemente varía considerablemente entre individuos, dependiendo tanto de la constitución genética (eficacia en la producción de colesterol en comparación con la absorción) y al suministro de colesterol en la dieta ${ }^{22}$.

Las dos principales fuentes del colesterol celular se derivan de la síntesis de novo y la captación de lipoproteínas plasmáticas. El colesterol se sintetiza a partir de acetil CoA a través de una serie de más de 30 reacciones enzimáticas ${ }^{24}$, las cuales pueden ser resumidas en tres etapas, la primera consiste en la síntesis de pirofosfato de isopentenilo, que es la unidad de construcción fundamental de colesterol; seguida de la condensación de seis moléculas de pirofosfato de isopentenilo para formar escualeno, y finalmente, el escualeno se cicla para formar lanosterol, que después de una serie de reacciones se convierte en colesterol ${ }^{24}$. 
La segunda fuente de colesterol celular ocurre a través de la captación de colesterol asociado a las lipoproteínas de baja densidad (LDL) mediante el receptor de las LDL (LDLR), pero también de colesterol en forma de lipoproteínas de alta densidad (HDL-C) y de remanentes de quilomicrones por receptores específicos ${ }^{22}$.

La homeostasis de colesterol intracelular, en los hepatocitos, se mantiene a través de una red coordinada que implica la participación de diversos genes involucrados en su captación, síntesis, bio-transformación, excreción y eflujo celular (Figura 1). La síntesis del colesterol está estrechamente regulada por el factor de transcripción de la proteína 2 de unión al elemento regulador de esteroles(SREBP-2). La forma madura de SREBP-2 inducida por SP-2 activa genes específicos en la biosíntesis del colesterol, tal es el caso de la enzima hidroximetilglutaril CoA reductasa (HMGCR), pieza clave en la regulación de la síntesis de colesterol ${ }^{22,25}$. De manera interesante, SREBP-2 también regula la captación hepática de colesterol, a través de la expresión hepática del receptor LDLR ${ }^{25,26}$. De tal manera, que cuando las células requieren colesterol, el factor de transcripción SREBP-2 aumenta la expresión de ambos, la HMGCR y el LDLR, resultando en un incremento en la síntesis y captación de colesterol $^{27}$ (Figura 1).

Por otra parte, el procesamiento del colesterol tiene lugar en diferentes localizaciones subcelulares; por lo tanto, la entrega de colesterol entre estos sitios es un medio importante para regular estas reacciones ${ }^{22}$. El colesterol se transfiere entre las membranas subcelulares por transporte vesicular y por mecanismos no vesiculares ${ }^{22}$. Las vesículas transportan componentes de la membrana a los orgánulos sub-celulares por medio de pistas en el citoesqueleto, mientras que los mecanismos de transferencia de colesterol no-vesiculares presumiblemente utilizan proteínas de transferencia de lípidos en el citosol'22.

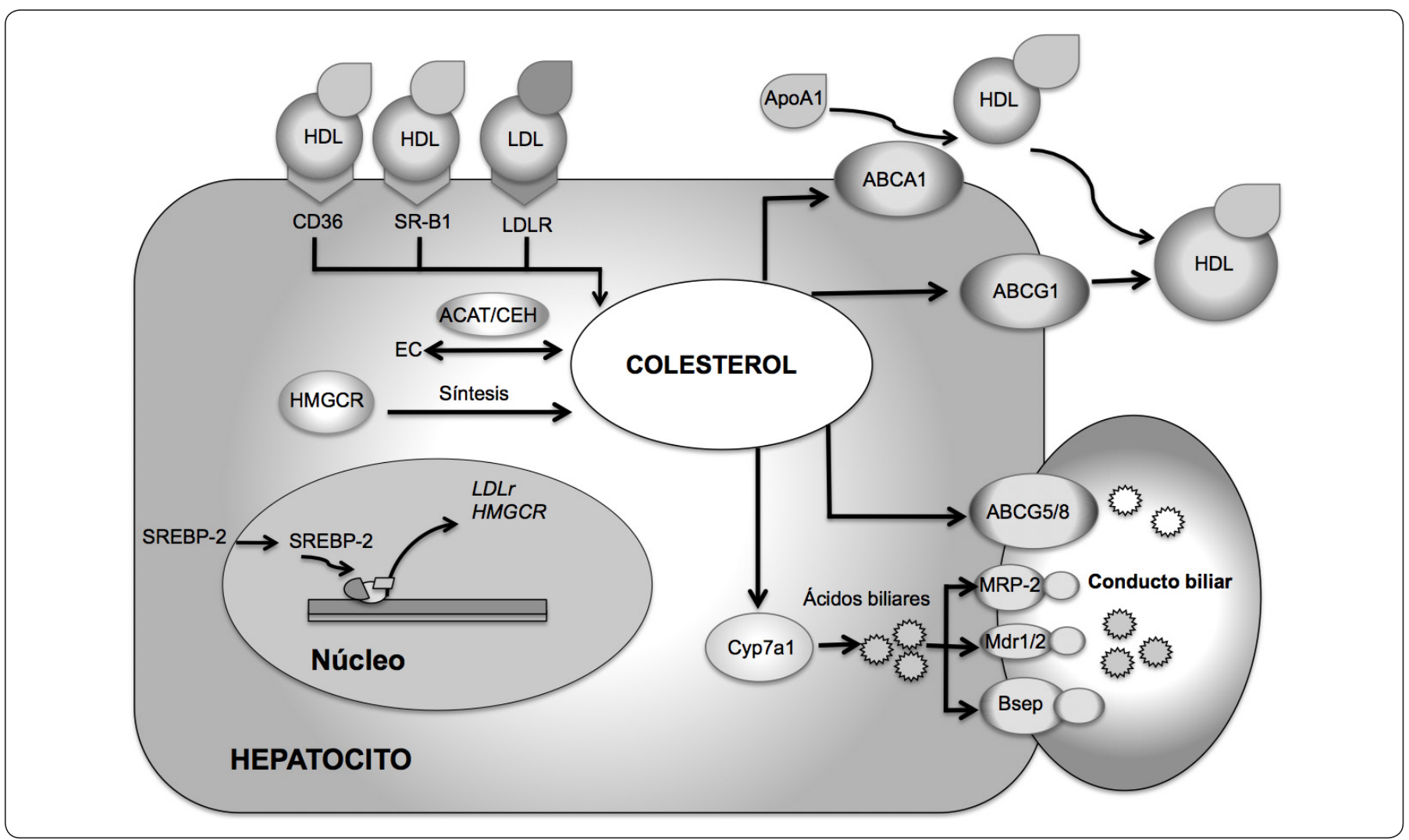

Figura 1. Homeostasis del colesterol. La homeostasis de colesterol intracelular está coordinada por diferentes vías metabólicas, por ejemplo: captación (CD36, SR-B1, LDL-R), síntesis (HMGCR), bio-transformación (CYP7A1), eflujo celular al conducto biliar (ABCG5/G8, MRP-2, Mdr1/2 y Bsep), eflujo celular hacia las HDL (ABCA1/G1); así como la regulación por factores de transcripción que censan los niveles de colesterol intracelular (SREBP-2). CD36, Proteína de transporte de ácidos grasos; SRB1, Receptor basurero clase B tipo 1; LDL-R, Receptor de las lipoproteínas de baja densidad; HMGCR, Hidroximetilglutaril CoA reductasa; Cyp7a1, Colesterol 7 alfa-hidroxilasa; ABCG5, Transportador G5 dependiente de unión a ATP; ABCG8, Transportador G8 dependiente de unión a ATP; MRP-2, Proteína asociada a resistencia a multidrogas-2; Mdr1/2, Proteína de resistencia a multidrogas-1/2, Bsep, Proteína 2 exportadora de sales biliares; ABCA1, Transportador A1 dependiente de unión a ATP, ABCG1, Transportador G1 dependiente de unión a ATP; SREBP-2, Proteína 2 de unión al elemento regulador de esteroles; ACAT2, la acetil- CoA acetiltransferasa 2; CEH, la colesterol éster hidrolasa; EC, ésteres de colesterol. Basado en ${ }^{28,29}$. 
En este sentido, la homeostasis del colesterol debe ser finamente regulada para mantener los niveles de colesterol en rangos adecuados y realice correctamente sus funciones biológicas.

\section{El alto consumo de colesterol en la dieta aumenta el riesgo de desarrollar HGNA}

El exceso en el consumo de colesterol se ha considerado como una causa fundamental del HGNA ${ }^{30,31,32}$. En modelos animales se ha observado que una dieta alta en colesterol, dentro de un rango de energía normal, induce el comienzo del HGNA y su progresión a otras complicaciones como inflamación, EHNA y fibrosis ${ }^{33,34,35}$. Por otra parte, en un estudio que incluyó un número amplio de pacientes, el consumo de colesterol en la dieta se asoció independientemente a mayor riesgo de cirrosis y cáncer hepático, mientras que el consumo de grasa total no mostró diferencias ${ }^{36}$. Además, una encuesta nutricional encontró que la ingesta de colesterol en la dieta fue significativamente mayor en pacientes con EHNA, que en sujetos saludables ${ }^{37}$. Otro grupo de investigadores encontró en pacientes obesos y no obesos, con HGNA, que la ingesta del colesterol fue significativamente más alta en los pacientes con HGNA, que en sujetos saludables ${ }^{38}$. En este mismo estudio, llama la atención que los pacientes no obesos con HGNA ingirieron más colesterol que los pacientes con HGNA obesos ${ }^{38}$, lo cual indica que la ingesta de colesterol en la dieta es esencial para el inicio y progresión del HGNA independiente de la obesidad ${ }^{39}$.

\section{Factores genéticos en el metabolismo del colesterol se asocian a HGNA}

Diversos factores genéticos que afectan el metabolismo del colesterol se han asociado a la progresión de esteatosis y EHNA. De manera muy interesante, en un estudio de seguimiento a 7 años, en sujetos sin presencia de obesidad o diabetes, se observó que los sujetos con el polimorfismo rs133291 (C/T) en el gen SREBP-2 predice la incidencia de HGNA, y la predisposición para desarrollar EHNA ${ }^{40}$. Además, de manera reciente se reportó la asociación del polimorfismo rs $2228314 \mathrm{G}>\mathrm{C}$ de este mismo gen, con el desarrollo de HGNA ${ }^{41}$. Por tanto, polimorfismos que afecten la función adecuada de SREBP-2 podrían exacerbar el efecto tóxico del colesterol, aun en ausencia de un consumo excesivo de este lípido en la dieta.

De manera similar, se ha observado que un polimorfismo en la farnesil- difosfato farnesil transferasa 1 (FDFT1), que codifica para la escualeno sintasa -enzima que cataliza el primer paso en la biosíntesis de esteroles- se ha asociado a EHNA ${ }^{42}$. A su vez, la deficiencia de la lipasa ácida lisosomal que es causada por mutaciones en el gen $L I P A$, desencadena esteatosis, fibrosis y cirrosis debido a la acumulación de esteres de colesterol y triglicéridos en los hepatocitos y en células de $\operatorname{Kupffer}(\mathrm{CKs})^{43,44}$. Recientemente, un estudio demostró que el reemplazamiento de este defecto, con una proteína LIPA recombinante, revierte este efecto en humanos ${ }^{45}$.
Lo anterior sugiere que el componente genético de esta patología en combinación con los factores ambientales, por ejemplo el alto consumo de colesterol en la dieta, podrían explicar, al menos en parte, la susceptibilidad para desarrollar HGNA y EHNA.

\section{Desequilibrio en la homeostasis del Colesterol hepático EN EL HGNA}

Los estudios en modelos animales con obesidad, diabetes o dislipidemias demuestran que el desequilibrio en la homeostasis de colesterol promueve su acumulación y modula la transición de esteatosis a EHNA, lo que correlaciona directamente con el grado de daño hepático, muerte celular por apoptosis, acumulación de macrófagos y fibrosis ${ }^{28}$. Además, Min y colaboradores (2012) encontraron en pacientes con EHNA que distintas rutas metabólicas involucradas en la homeostasis del colesterol hepático se encuentran desreguladas ${ }^{29}$.

\section{Biosíntesis de colesterol}

La HMGCR es la enzima limitante en la velocidad de la síntesis de colesterol ${ }^{46}$. Distintos estudios han revelado que la expresión y actividad de la HMGCR se incrementa en el hígado de pacientes con EHNA, y parece estar asociado a una disminución en los niveles de fosforilación de su forma activa ${ }^{18,29}$. También, se ha demostrado que la expresión de la HMGCR correlaciona directamente con la acumulación del colesterol y el daño hepático en sujetos con $\mathrm{HGNA}^{29}$, y revela a la HMGCR como posible pieza clave en el desarrollo a EHNA, a través de la acumulación de colesterol.

\section{Captación de lipoproteínas ricas en colesterol}

Además del receptor de las lipoproteínas de baja densidad (LDLR), el colesterol también puede ser captado a través del receptor basurero clase B tipo 1 (SR-B1) y la proteína de transporte de ácidos grasos CD36, las cuales funcionan como receptores de las lipoproteínas de alta densidad (HDL) ${ }^{47,48}$ (Figura 1). Diversos estudios demuestran que el receptor LDLR se encuentra sobre-regulado en modelos experimentales con esteatosis y EHNA, que podría contribuir al incremento en el contenido del colesterol hepático ${ }^{28,49}$; sin embargo, recientemente un estudio encontró que la expresión hepática del receptor LDLR decreció en sujetos con EHNA, aunado a un incremento en los niveles plasmáticos de las $\mathrm{LDLs}^{29}$. Por tanto, se requieren otros estudios para definir si el receptor LDLR participa en el desarrollo del HGNA. A su vez, la expresión hepática del receptor CD36 se encuentra sobre-regulada y correlaciona con la severidad de la esteatosis en pacientes con EHNA ${ }^{50}$. Estos hallazgos son congruentes con lo reportado en otro estudio experimental, en donde la ausencia de CD36, protege del desarrollo de esteatosis e inflamación hepática ${ }^{51}$. Por otra parte, la expresión del receptor SR-B1 se encuentra incrementada en modelos experimentales con $\mathrm{HGNA}^{52}$, lo cual sugiere un incremento en la captación de colesterol; sin embargo, otro estudio muestra que la transcripción de SR-B1 se encuentra 
disminuida en EHNA en el modelo murino ${ }^{28}$. Estudios futuros serán necesarios para clarificar esta discrepancia.

\section{Regulación de colesterol por SREBP-2}

SREBP-2 es un factor de transcripción clave en la regulación de los niveles de colesterol en estados de resistencia a la insulina e hiperinsulinemia, ambos comunes en los pacientes con esteatosis y EHNA. Llama la atención que la expresión hepática de SREBP-2 está incrementada en pacientes con EHNA $^{18}$, y es consistente con otros casos reportados ${ }^{28,29,53}$. Recientemente, un estudio demostró también que SREBP-2 contribuye a la acumulación de CL en células estelares hepáticas (CEHs), lo que condujo al desarrollo de EHNA y fibrosis ${ }^{53}$. Por tanto, estos resultados sugieren que SREBP-2 juega un papel importante en la progresión a EHNA y fibrosis, por lo que futuras investigaciones serán requeridas para determinar si SREBP-2 podría ser un blanco terapéutico para la prevención y/o tratamiento de la EHNA y fibrosis.

\section{PPARs en la homeostasis del colesterol}

Diversos estudios indican que la homeostasis del colesterol puede ser modulada por el efecto de los receptores activados por proliferadores de peroxisomas (PPARs) ${ }^{54-56}$. De hecho, se ha observado en modelos murinos con procesos inflamatorios hepáticos, que los niveles de expresión de PPAR- $\alpha$ se encuentran reducidos, sugiriendo una disminución en el eflujo de colesterol, a través de la regulación de la expresión de su gen blanco, el transportador de colesterol A1 dependiente de unión a ATP (ABCA1, por sus siglas en inglés) ${ }^{57}$. Además, recientemente en un modelo de ratón carente de PPAR- $\alpha$, los niveles de colesterol aumentaron en el hígado, aunado a un incremento en el daño hepático ${ }^{58}$. De manera adicional, en el humano, se ha observado que los niveles de expresión hepática de PPAR- $\alpha$ correlacionan inversamente con la severidad de la EHNA $^{59}$. Lo anterior sugiere que PPAR- $\alpha$, en parte, a través de la regulación de la homeostasis del colesterol, podría ser un blanco terapéutico potencial en el tratamiento de la EHNA.

Por otra parte, se ha observado también en CEHs activadas, que la supresión de PPAR- $\gamma$ disminuye la expresión del gen 1 inducido por insulina (Insig-1, por sus siglas en inglés), cuyo resultado es la disrupción del sistema de retro-alimentación en la homeostasis del colesterol, mediado por SREBP- $2^{53}$. Lo anterior conduce al incremento del colesterol libre en las CEHs, y su posterior activación; lo que desencadena procesos fibrogénicos y $\mathrm{EHNA}^{53}$.

\section{Transporte de colesterol intracelular}

El colesterol es insoluble en agua, por tanto, requiere ciertos mecanismos especializados para moverse a través de los organelos en el citosol. Se ha sugerido que el desequilibrio en estos mecanismos aumenta la acumulación de CL y la toxicidad en ciertos compartimentos celulares, lo que promueve el desarrollo de la EHNA ${ }^{60,61}$.
La caveolina-1 es la principal proteína estructural de las caveolas, que son bolsas lipídicas con alto contenido de colesterol y esfingolípidos ${ }^{62}$. Además, la caveolina-1 juega una participación importante en el transporte intracelular del colesterol $^{62}$. Consistente con ello, un modelo experimental con HGNA mostró que los niveles de expresión de la caveolina-1 aumentaron significativamente alrededor y dentro de las gotas de lípidos (GLs), así como dentro de la membrana interna de la mitocondria ${ }^{63}$. Estos hallazgos sugieren que la caveolina-1 participa en la lipogénesis anormal y en la función mitocondrial típica de los hepatocitos esteatóticos en el HGNA.

Las proteínas Niemannn-Pick C1 y C2 (NPC1 y NPC2) se encuentran en las membranas de los lisosomas y los endosomas tardíos; presentan una participación crítica en la regulación del tráfico de colesterol intracelular, de los compartimentos endolisosomales al resto de la célula ${ }^{64}$. Mutaciones en los genes $N c p 1$ y $N c p 2$ se relacionan con la enfermedad Niemannn-Pick ${ }^{65,66,67}$, que es una enfermedad caracterizada por la acumulación de CL en la mayoría de los tejidos incluido el hígado ${ }^{65,67}$. De manera interesante, se ha observado que la deficiencia de NPC1/2 conduce a HGNA, ganancia de peso y síndrome metabólico en modelos experimentales ${ }^{68}$. Lo que permite sugerir que NCP1 y 2 podrían contribuir al desarrollo del HGNA.

La familia de proteínas de transferencia de lípidos relacionadas a StAR (START) está implicada en la transferencia de lípidos intracelulares ${ }^{69}$. Particularmente, la proteína de regulación aguda de esteroidogénesis (StAR) facilita el movimiento de colesterol de los almacenamientos celulares a la mitocondria ${ }^{70}$. De manera interesante, Caballero y colaboradores (2009) encontraron que los niveles de mRNA de StAR están incrementados 7 y 15 veces en pacientes con esteatosis y EHNA $^{18}$. Lo que sugiere que la acumulación de CL en la mitocondria, regulado por StAR, podría jugar un papel importante en la progresión de la enfermedad. De manera similar, la proteína endosomal MLN64 (por sus siglas en inglés, metastatic lymph node protein 64) modula el eflujo de colesterol de los endosomas a la mitocondria ${ }^{71}$. Por lo que a MLRG4 se le ha propuesto como una proteína candidato, en el aumento del transporte del colesterol a la mitocondria, y en el desarrollo del HGNA ${ }^{60}$. De hecho, la sobre-expresión de MLRG4 induce un incremento en los niveles de CL hepático, asociada con apoptosis y daño en el hígado ${ }^{72}$. Sin embargo, en otro estudio se observó que los niveles de expresión hepática de MLRG4 disminuyeron en ratones obesos modificados genéticamente, y los autores proponen que MLRG4 podría proteger al hígado del efecto lipotóxico.

Otra proteína que parece ser importante en la regulación del tráfico de colesterol intracelular, es la proteína de unión a oxiesteroles (OSBP, por sus siglas en inglés) y proteínas asociadas a OSBP. OSBP es una proteína citosólica que 
se le ha implicado en la regulación del colesterol celular, esfingomielina, $\mathrm{y}$ transporte de oxiesteroles ${ }^{73}$. Aunque no hay una conexión directa entre los miembros de la familia OSBP y el HGNA, un estudio reveló que ORP8 -un miembro de esta familia-juega un papel importante en la homeostasis de lípidos ${ }^{74}$ y también la sobre-expresión de ORP8 redujo los niveles de colesterol y triglicéridos hepáticos, mientras que el silenciamiento los incrementó a través de la modulación de la expresión de la proteína 1 y 2 de unión al elemento regulador de esteroles (SREBP-1 y 2) ${ }^{74}$. Por tanto, investigaciones adicionales serán requeridas para definir la participación de las proteínas OSBP en el desarrollo del HGNA.

\section{Eflujo de colesterol y transportadores de colesterol ABCA1/ G1}

El transportador de colesterol ABCA1, es una proteína integral de la membrana, que participa en el transporte reverso del colesterol. Esta proteína se ha estudiado ampliamente, debido a su estrecha relación con las concentraciones plasmáticas del HDL-C. La lipidación de apoA-1 mediante el transportador ABCA1 es un paso limitante en la velocidad del transporte reverso del colesterol y la generación de HDLs en el plasma ${ }^{75}$. Por ello, un transporte eficiente o eflujo de colesterol podría ser clave en la prevención del desarrollo a EHNA. Recientemente, se reportó que la sobre-expresión de la proteína de ABCA1 disminuye significativamente el contenido de ácidos grasos libres, triglicéridos y colesterol en células hepáticas, mientras que el silenciamiento de ABCA1 incrementa los niveles de estos lípidos ${ }^{76}$. Además, se sabe que el hígado de ratas con EHNA expresan niveles bajos de la proteína $\mathrm{ABCA1}$, pero no de los niveles de expresión del mRNA ${ }^{77}$. De manera similar, se encontró que sólo los niveles de la proteína ABCA1 se encuentran reducidos en sujetos con $\mathrm{EHNA}^{78}$. Lo cual sugiere mecanismos de regulación post-transcripcional regulando los niveles de la proteína ABCA1 en la $\mathrm{EHNA}^{78}$. En este estudio, el nivel de expresión de miR-33a - un regulador post-trancripcional de $\mathrm{ABCA} 1$ - correlacionó negativamente con los niveles de la proteína ABCA1 y positivamente con la severidad de la enfermedad ${ }^{78}$. Lo que podría explicar la discrepancia observada entre los niveles de mRNA y proteína. Con base en los resultados anteriores, se sugiere que ABCA1 podría contribuir a la patogénesis del HGNA, posiblemente a través de la modulación del colesterol.

Por otra parte, se ha observado en modelos murinos, que la ausencia del transportador de colesterol G1 dependiente de unión a ATP (ABCG1, por sus siglas en inglés) promueve la acumulación de lípidos en hepatocitos y macrófagos ${ }^{79}$. Además, ABCG1 promueve el eflujo de ciertos oxi-esteroles lipotóxicos (como el 7-cetocolesterol) ${ }^{80}$. De manera interesante, se ha encontrado que los niveles de la proteína ABCG1 se encuentran reducidos en sujetos con EHNA ${ }^{45,78}$. Por tanto, ABCG1 podría contribuir al HGNA a través de la modulación del colesterol. Sin embargo, se requieren otros estudios, en modelos experimentales, que definan si la disminución de ABCG1 es causa de EHNA.

\section{Excreción y bio-transformación de colesterol}

La regulación de los niveles de colesterol también implica su excreción al conducto biliar a través de diferentes vías, en las que participan los transportadores de colesterol G5 y G8 dependientes de unión a ATP (ABCG5 y ABCG8, por sus siglas en inglés) ${ }^{75,81}$ (Figura 1). De manera interesante, ratones que carecen de los transportadores ABCG5/8 muestran una reducción en la secreción de colesterol al conducto biliar y son más susceptibles al desarrollo de esteatosis, resistencia a la insulina hepática, y pérdida del control de la glucemia cuando son alimentados con un dieta alta en grasa ${ }^{82}$. Además, Min y colaboradores (2012) encontraron que los niveles de expresión de ABCG8 se encuentran reducidos en sujetos con EHNA ${ }^{29}$. Estos resultados soportan la hipótesis de que la reducción en el eflujo del colesterol a través del conducto biliar, vía ABCG5/8, podría contribuir al desarrollo de la EHNA.

De manera similar, la bio-transformación hepática del colesterol en ácidos biliares (ABs) constituye la principal ruta del catabolismo del colesterol, en donde la colesterol 7-alfahidroxilasa (Cyp7a1) es la enzima limitante en la velocidad de producción del $90 \%$ de los ABs a partir de colesterol (Figura 1). De manera interesante, niveles reducidos de Cyp7a1 se observaron en un modelo de rata con EHNA inducido por incremento de colesterol en la dieta ${ }^{83}$. Además, los niveles de proteína de Cyp7a1 y Cyp27a se encuentran reducidos en sujetos con EHNA $^{29}$. Por tanto, la reducción en la biotransformación del colesterol podría también contribuir a la acumulación del colesterol hepático, y posiblemente a la progresión a EHNA.

\section{Esterificación y des-esterificación de colesterol}

La relación dinámica entre ésteres de colesterol (EC) y CL está dada por la esterificación y des-esterificación llevada acabo por dos enzimas del RE: la acetil-CoA acetiltransferasa 2 (ACAT2) y la colesterol éster hidrolasa (CEH). Aunque la participación de ACAT2, en el desarrollo del HGNA, parece no ser concluyente, debido a la discrepancia de los resultados encontrados ${ }^{18,28,29,84}$, los niveles de expresión de CEH se encuentran incrementados en un estudio que incluye pacientes con EHNA ${ }^{29}$. Estos hallazgos sugieren que $\mathrm{CEH}$ contribuye al incremento en el contenido de $\mathrm{CL}$, mediante la inducción de la hidrólisis de EC, aumentando el contenido de CL, lo que podría desencadenar EHNA.

\section{MicroRNAs en la modulación del colesterol hepático}

Recientemente, además de la regulación transcripcional clásica, una clase de RNAs no codificantes denominados microRNAs (miRNAs), constituidos de $\sim 23 \mathrm{nt}$ de RNA endógeno, se han presentado como reguladores de la expresión y actúan predominantemente a nivel post-transcripciona ${ }^{85,86}$. En laúltima década, se ha demostrado de manera más clara y progresiva que 
los microRNAs funcionan como reguladores importantes de un amplio rango de procesos celulares, incluyendo el metabolismo del colesterol ${ }^{85,87,88}$ y se ha identificado que la alteración en los perfiles de los microRNAs está asociada con esteatosis y EHNA $^{89-91}$

De manera interesante, distintos microRNAs se han relacionado a EHNA y al metabolismo del colesterol hepático, lo que sugiere que estas micro-moléculas podrían contribuir a la progresión de la EHNA a través de la modulación de los niveles de colesterol hepático. Por ejemplo, miR-34a se le ha implicado como un factor central en el desarrollo de la EHNA $^{91}$. El mejor blanco caracterizado para miR-34a es la sirtruina 1 (SIRT1), una desacetilasa dependiente de NAD, la cual disminuye los niveles de la HMGCR fosforilada ${ }^{29}$. De manera interesante, miR-34a se encuentra sobre-expresado en sujetos con $\mathrm{EHNA}^{89,92}$. Además, se ha sugerido que el incremento de miR-34a puede modular la fosforilación de la HMGCR y mantenerla en su forma activa, aumentando los niveles de CL hepático ${ }^{29}$. Por tanto, estos resultados sugieren que cambios en la expresión de miR-34a podrían contribuir al desarrollo de la EHNA, al menos en parte, a través de la modulación de la HMGCR.

Otro microRNA de relevancia es miR-122, el microRNA más abundante en el hígado y comprende aproximadamente el $70 \%$ de los microRNAs expresados en él ${ }^{93,94}$. Encontrándose que miR-122 es un regulador clave en el metabolismo del colesterol y los ácidos grasos ${ }^{95,96}$. Llama la atención que miR122 se encuentra disminuido en sujetos con $\mathrm{EHNA}^{89,92}$. De manera interesante, estudios funcionales demostraron que el silenciamiento de miR-122, en células HepG2, conduce a un incremento inicial de sus genes blanco: Hmgcr y Srebp-2, que son claves en la síntesis del colesterol ${ }^{89}$. De manera contradictoria, en modelos murinos, se ha observado que el silenciamiento de miR-122 resulta en una reducción del 25$30 \%$ en los niveles de colesterol plasmático, aunado a una reducción hepática en la expresión de genes que participan en la síntesis del colesterol: 3-hidroxi-metilglutaril-CoA sintetasa 1 (Hmgcs 1), 7-dehidrocolesterol reductasa (Dhcr7) y $\mathrm{Hmgcr}^{97}$. En un modelo de ratón alimentado con una dieta alta en grasa, se ha observado que la inhibición de miR122 induce una disminución significativa en la síntesis de colesterol y ácidos grasos ${ }^{95}$. Por tanto, lo anterior sugiere que la regulación de miR-122 en humanos es distinta al modelo murino, y será de relevancia determinar en primates no humanos el efecto de la inhibición o inducción de miR-122 en el desarrollo del HGNA.

Recientemente, se ha demostrado que miR-21 se encuentra disminuido en el modelo de ratón y en sujetos con HGNA ${ }^{98,99}$. Además, en modelos in vitro con HGNA, se ha observado que la disminución de miR-21 aumenta la expresión de su gen blanco la Hmgcr; por el contrario, análogos de miR-21 disminuyen los niveles de TG, CL y colesterol total ${ }^{99}$. Por tanto, estos resultados sugieren que miR-21 contribuye a la modulación del colesterol hepático, y posiblemente al desarrollo del HGNA.

Mir-33 es otro microRNA que está involucrado en la regulación de la homeostasis del colesterol y oxidación de los ácidos grasos $^{100,101}$. En humano se han identificado dos isoformas de miR-33: miR-33a y miR-33b; mientras que en ratón, hay sólo un gen miR-33, conservado con el miR-33a de humano ${ }^{100,101}$. El gen miR-33a está localizado en el intrón 16 del gen Srebp-2 y miR33 b está presente en el intrón 17 del gen Srebp- $1^{100,101}$. En una gran cantidad de estudios se ha demostrado que la sobre-expresión de miR-33, en hepatocitos y macrófagos, resulta en la disminución de la expresión de ABCA1 y del eflujo de colesterol ${ }^{101-104}$. De igual manera, la inhibición endógena de miR-33, en el mismo tipo de células, promueve un incremento tanto en la expresión de ABCA 1 como en el eflujo de colesterol $^{101-103}$. Estos resultados son congruentes en estudios de primates no humanos, en donde la inhibición de miR-33 aumentó los niveles de expresión de ABCA1 y el eflujo de colesterol ${ }^{105}$. Recientemente, se observó que los niveles de expresión hepática de miR-33a, pero no miR$33 \mathrm{~b}$, correlacionaron negativamente con la expresión de su gen blanco Abcal en biopsias de pacientes con HGNA, además, miR-33a aumentó de manera progresiva con el desarrollo a EHNA $^{78}$. Este resultado es consistente con lo publicado por Lendvai y colaboradores (2014) en donde los niveles de miR33 a se encontraron elevados en sujetos con $\mathrm{HGNA}^{106}$. Además, estudios recientes, en modelos murinos, sugieren que la acumulación de CL en CEHs promueve el desarrollo de EHNA a fibrosis hepática, posiblemente a través del incremento de los niveles de miR-33a, lo que podría conllevar a la supresión de los niveles de ABCA1 y del eflujo de colesterol ${ }^{53}$. Con base en lo anterior, miR-33a podría contribuir a la acumulación del colesterol hepático, al desarrollo de la EHNA y fibrosis, al menos en parte, a través de la regulación de ABCA1. Por tanto, será de relevancia definir si miR-33a está involucrado en la progresión de EHNA a fibrosis hepática en el humano, y si una modulación terapéutica de miR-33a podría ser útil para el tratamiento de la fibrosis.

El microRNA-144 también regula la expresión hepática de ABCA1 en modelos murinos, y en cultivos celulares de macrófagos humanos, promueve la acumulación de colesterol hepático, atenuando el eflujo de colesterol a través de apo-A ${ }^{107-109}$ siendo consistente con la asociación de miR-144 con los niveles de la proteína ABCA1 y con niveles incrementados en sujetos con $\mathrm{EHNA}^{78}$.

Lo anterior sugiere que un desequilibrio en la vías metabólicas, que participan en la homeostasis del colesterol en el hígado, podría promover la acumulación de colesterol, y desencadenar daño hepático a distintos niveles celulares, promoviendo la progresión de EHNA y fibrosis. 


\section{El COlesterol en LA tOXICIDAD CELULAR Y PATOGÉnESIS DEL HGNA}

Toxicidad del colesterol en el HGNA

A diferencia de la membrana plasmática (MP) que contiene altas concentraciones de colesterol, el retículo endoplasmático (RE) y la mitocondria poseen una cantidad menor de colesterol (3-5\% del colesterol celular total $)^{110}$ y son altamente sensibles a la pérdida de fluidez membranal ocasionada por enriquecimiento de colesterol ${ }^{111}$.

Se ha demostrado que niveles elevados de CL afectan la organización y las propiedades físicas de las membranas mitocondriales y del RE, lo que disminuye la fluidez de las membranas ${ }^{112}$. Estos eventos afectan negativamente a ciertas proteínas transmembranales, que requieren libertad conformacional para realizar sus funciones de manera apropiada $^{113}$ (Figura 2).

\section{Disfunción mitocondrial por colesterol}

Estudios realizados, en modelos murinos y en cultivos primarios de hepatocitos, demostraron que el exceso de CL en la mitocondria hace sensible al hepatocito a citocinas a través de la depleción del glutatión mitocondrial ( $\mathrm{mGSH}$, por sus siglas en inglés), que es esencial para controlar la generación de especies reactivas de oxígeno (ERO). Ésto sucede a través del incremento del CL en la mitocondria que reduce la fluidez de su membrana y afecta la estabilidad de la proteína transmembranal acarreadora de 2-oxoglutarato, que transporta glutatión del citosol al interior de la mitocondria ${ }^{14}$. En consecuencia, los niveles de glutatión reducen en la mitocondria, y los hepatocitos se vuelven sensibles a citocinas inflamatorias como el factor de necrosis tumoral $\alpha$ ( $\mathrm{TNF} \alpha$, por sus siglas en inglés) y la molécula pro-apoptótica Fas. Lo anterior promueve la permeabilización de la membrana mitocondrial, la liberación del citocromo C, necrosis y apoptosis; e inflamación hepática y EHNA en modelos experimentales ${ }^{114}$.

Estrés en el retículo endoplasmático (RE) inducido por colesterol

Algunos estudios sugieren que la acumulación del colesterol en la membrana del RE altera sus funciones y su capacidad para el correcto plegamiento de proteínas ${ }^{15,116}$, ésto resulta en una condición conocida como estrés del RE o respuesta a proteínas mal plegadas (UPR, por sus siglas en inglés). Se sabe que esta condición juega un papel importante en desórdenes asociados a la obesidad, incluyendo el HGNA ${ }^{117}$. Un ejemplo de ello, son los desórdenes conformacionales de la ATPasa de $\mathrm{Ca}^{2+}$ del retículo sarco(endo)plásmico (SERCA, por sus siglas en inglés, ER sarco(endo) plasmic reticulum $\mathrm{Ca}^{2+}$-ATPase), que es altamente sensible a incrementos mínimos en los niveles de colesterol en el $R E, y$ afecta su actividad ATPasa ${ }^{118,119}$. En consecuencia las altas concentraciones fisiológicas de $\mathrm{Ca}^{2+}$ dentro del RE disminuyen y como resultado, se pierde la capacidad del correcto plegamiento de proteínas; lo que conduce a estrés en $\mathrm{RE}^{118,119}$. Sin embargo, aunque se ha descrito la importancia de la acumulación del CL

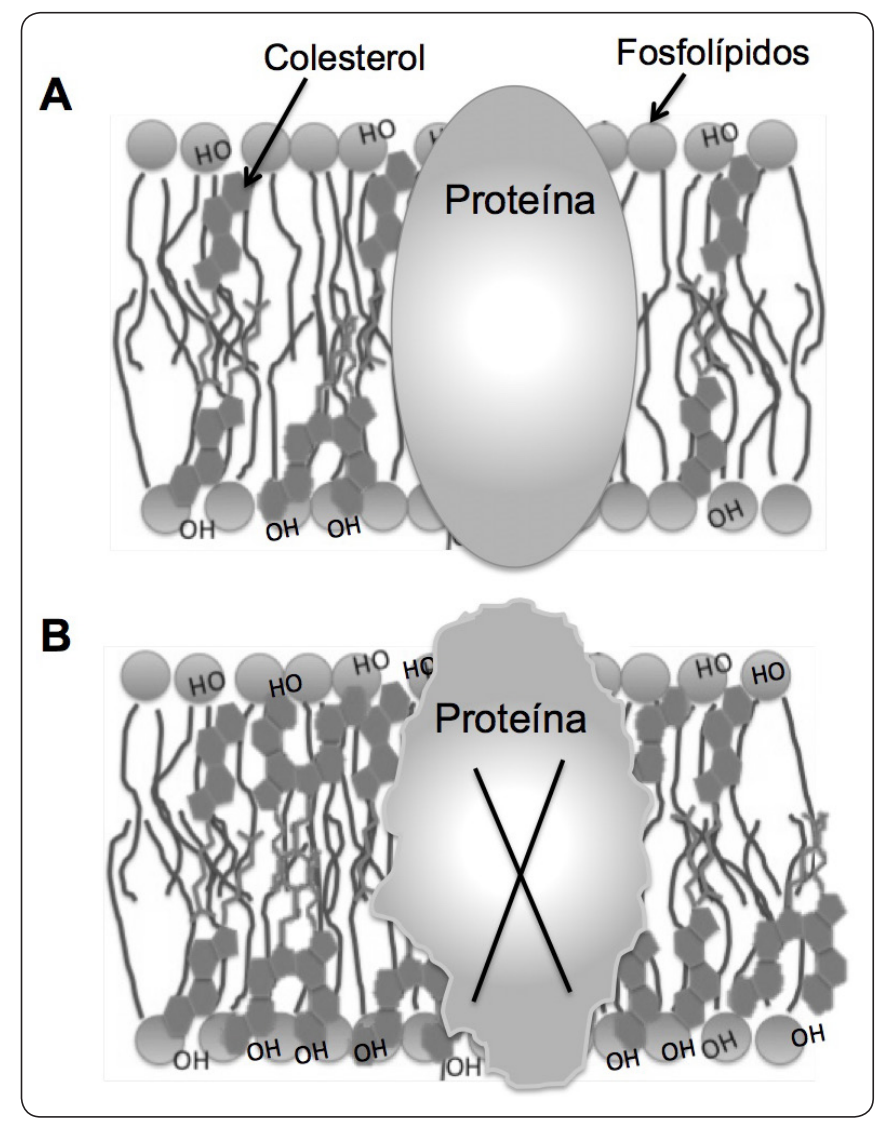

Figura 2. El aumento de colesterol en la membrana altera su estructura. (A) El colesterol se encuentra anclado estratégicamente en las membranas de la célula, donde modula la fluidez y permeabilidad. La molécula de colesterol constituye el elemento estructural básico del esqueleto de las membranas celulares, sin su refuerzo las membranas serían extremadamente fluidas y perderían su consistencia. (B) El aumento de los niveles de colesterol en la membrana afecta la organización y sus propiedades físicas, lo que disminuye la fluidez y aumenta la rigidez. En consecuencia, estos eventos afectan negativamente a ciertas proteínas transmembranales, las cuales requieren libertad conformacional para realizar sus funciones de manera apropiada. Basado en ${ }^{21,112}$.

en el RE en hepatocitos ${ }^{115,116}$, aún se desconoce la implicación que pudiera tener en el desarrollo a EHNA.

Inducción de células de Kupffer (CKs) y activación de células estelares hepáticas (CEHs) por colesterol

Las células de Kupffer (CKs) representan un 20-25\% de las células no-parenquimatosas del hígado. Además de su participación, bien conocida como células fagocíticas, las CKs activadas representan una fuente principal de citocinas pro-inflamatorias y pro-fibrogénicas (TNF- $\alpha$ y el factor de crecimiento transformante beta 1, TGF- $\beta 1)^{61}$. Asimismo, se ha demostrado, en modelos murinos con una dieta alta en grasa y colesterol, que la acumulación de CL en CKs es requerida para 
la activación de un fenotipo pro-inflamatorio, lo cual conduce al desarrollo de EHNA ${ }^{120}$. Por otra parte, debido a que las CKs no sintetizan colesterol, ellas lo obtienen principalmente a través de la captación de las lipoproteínas de baja densidad en estado oxidado (oxLDLs). Llama la atención, que la acumulación de colesterol lisosomal en las CKs promueve una respuesta inflamatoria, y causa incremento en la inflamación hepática en modelos experimentales con EHNA ${ }^{121,122}$. Se ha observado que el efecto de ciertos agentes, que reducen la acumulación de colesterol en los lisosomas, da como resultado una reducción en la inflamación hepática en modelos experimentales con EHNA $^{123,124}$. Sin embargo, se requerirán más estudios para definir si la captación sobre-regulada de las oxLDL en CKs conduce a la acumulación de colesterol, y promueve un respuesta inflamatoria en el desarrollo del HGNA en el humano.

Por otra parte, la activación de las células estelares hepáticas (CEHs) participa en procesos fibrogénicos en el desarrollo del HGNA $^{125}$. Evidencias recientes en modelos murinos, revelaron que la acumulación de CL intracelular activa directamente las CEHs, y las vuelve sensibles a la inducción por TGF- $\beta$. En consecuencia, se disparan procesos fibrogénicos mediados por el receptor tipo toll-4 (TLR4, por sus siglas en inglés), lo que conduce al incremento de la fibrosis en la EHNA ${ }^{53,126}$. Recientes investigaciones muestran que la eliminación de la acetil-CoA acetiltransferasa 1 (ACAT1), principalmente expresada en CEHs, exacerba la fibrosis hepática a través de la acumulación de CL en este tipo de células ${ }^{127}$.

\section{Cristales de colesterol y EHNA}

A los cristales de colesterol se les ha implicado en la activación del inflamasoma en lesiones arterioescleróticas ${ }^{128,129}$; por tanto, se ha sugerido que este proceso podría ocurrir de manera similar en EHNA $^{12,60}$. Por ejemplo, tanto en un modelo de ratón con dieta alta en colesterol, como en sujetos con EHNA, se ha observado que los cristales de colesterol están presentes en las gotas de lípidos, y forman estructuras tipo corona, que conduce a la producción de citocinas pro-inflamatorias, y activación de CKs y CEH ${ }^{130,131}$. Recientemente, se ha propuesto un modelo que describe el mecanismo de los cristales de colesterol en el desarrollo a EHNA ${ }^{12}$ : 1) La cristalización del colesterol ocurre en los hepatocitos esteatóticos inicialmente en la periferia de las gotas de lípidos largas, lo cual activa el inflamasoma NLRP3 en los hepatocitos, en consecuencia aumenta la producción de quimiocinas y citocinas pro-inflamatorias (IL-1 $\beta$, interleucina 1 beta). 2) En respuesta a señales quimiostáticas producidas por los hepatocitos, las CKs se agregan alrededor de los hepatocitos necróticos, que contienen cristales de colesterol, y forman estructuras tipo corona. 3) La exposición de las CKs a los cristales de colesterol causa activación del inflamasoma NLRP3 dentro de las CKs, lo cual conduce a la producción de citocinas pro-inflamatorias y quimiocinas, y en consecuencia se promueve inflamación crónica característica de la EHNA; las CKs expuestas a CL se transforman a células espumosas activadas cargadas de lípidos. 4) Las señales quimiostáticas producidas por la activación de las CKs atrae infiltrado inflamatorio adicional de otras CKs y neutrófilos, así como agregación, activación y transformación de las células estelares a miofibroblastos productores de colágena, lo cual conduce a fibrosis, y en el último de los casos cirrosis ${ }^{12,130,131}$ (Figura 3).

\section{CONCLUSIONES}

El HGNA es la forma más común de enfermedad hepática crónica. Además, la EHNA podría llegar a ser la causa líder de cirrosis y hepatocarcinoma en los siguientes 10 a 20 años ${ }^{10}$. Sin embargo, el conocimiento actual de los mecanismos involucrados en la progresión a EHNA y fibrosis, son escasos. Por lo que un mejor entendimiento de la patogénesis del HGNA podría ayudar a direccionar las propuestas terapéuticas para el tratamiento de la EHNA $^{29,60}$.

La asociación entre el alto consumo de colesterol, así como niveles incrementados de CL y alteraciones en la homeostasis del colesterol hepático, en sujetos con EHNA, ha conducido al estudio de los mecanismos moleculares involucrados en la lipotoxicidad hepática del colesterol. En este sentido, se ha observado que el CL puede causar disfunción mitocondrial y del RE, así como activar CKs y CEHs e inducir inflamación y fibrosis, condiciones que caracterizan a la EHNA. Por lo que actualmente, se ha considerado al CL como una molécula clave en la progresión de la enfermedad.

Llama la atención que aunque distintos mecanismos moleculares en la lipotoxicidad del colesterol se han descrito principalmente en modelos experimentales, aún hace falta evaluar si contribuyen a la patogénesis de la EHNA en humanos; así como determinar, si los genes que participan en la homeostasis del colesterol, podrían ser blancos terapéuticos en la prevención y/o tratamiento de la EHNA y fibrosis.

\section{Referencias}

1. Hamaguchi, M., Kojima, T., Takeda, N., Nakagawa, T., Taniguchi, H., Fujii, K., Omatsu, T., Nakajima, T., Sarui, H., Shimazaki, M., Kato, T., Okuda, J. \& Ida, K. The metabolic syndrome as a predictor of nonalcoholic fatty liver disease. Ann. Intern. Med.143(10): 722-728 (2005).

2. Fan, J-G., Zhu, J., Li, X-J., Chen, L., Li, L., Dai, F., Li, F. \& Chen, S-Y. Prevalence of and risk factors for fatty liver in a general population of Shanghai, China.J. Hepatol.43(3): 508-514(2005). DOI:10.1016/j.jhep.2005.02.042.

3. Tiniakos, D.G., Vos, M.B. \& Brunt, E.M. Nonalcoholic fatty liver disease: pathology and pathogenesis. Annu. Rev. Pathol. 5: 145-171 (2010). DOI:10.1146/annurev-pathol-121808-102132.

4. Kleiner, D.E., Brunt, E.M., Van Natta, M., Behling, C., Contos, M.J., Cummings, O.W., Ferrell, L.D., Liu, Y-C., Torbenson, M.S., Unalp-Arida, A., Yeh, M., McCullough, A.J. \& Sanyal, A.J. Nonalcoholic Steatohepatitis Clinical Research Network. Design and validation of a histological scoring system for nonalcoholic 


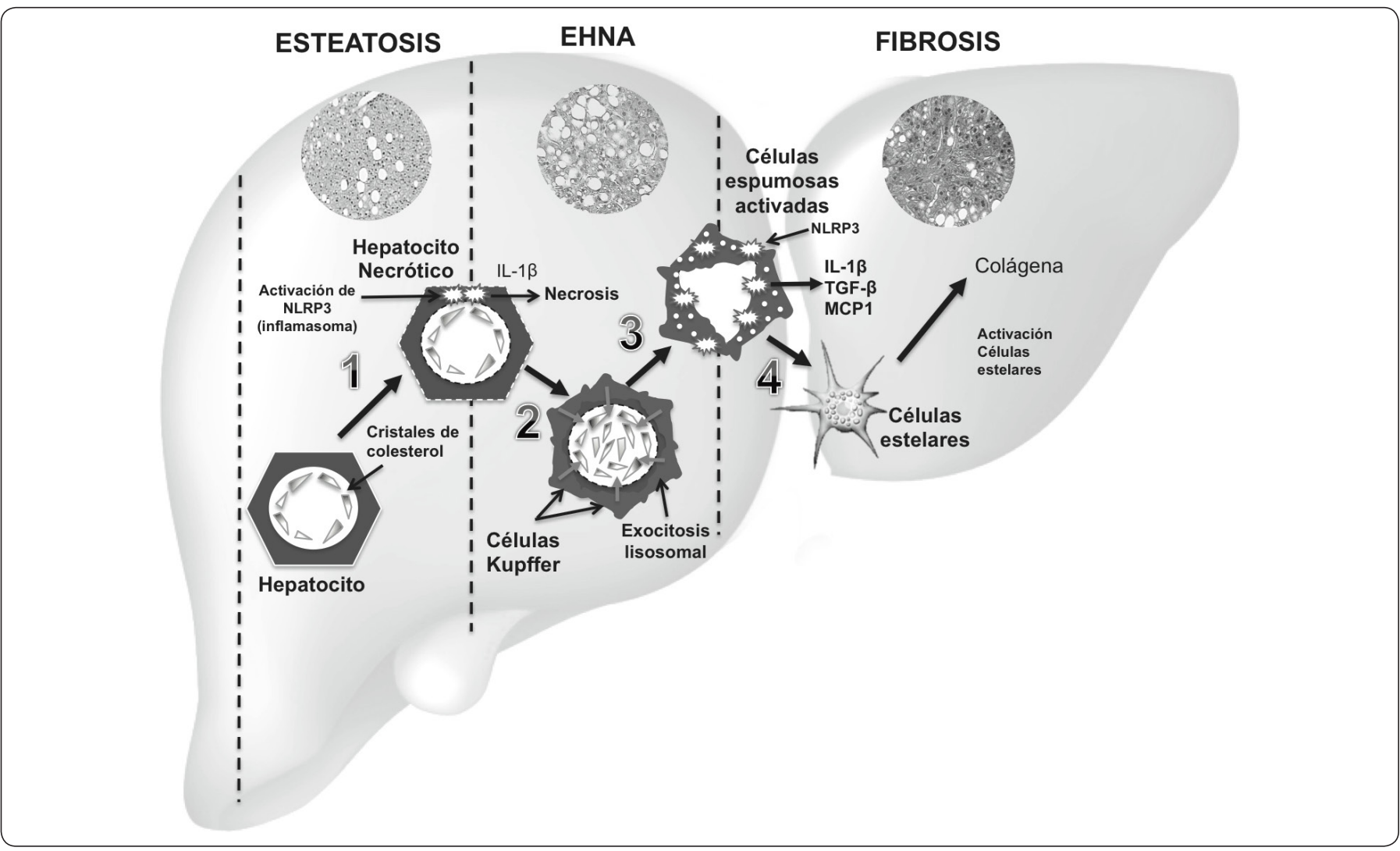

Figura 3. - Modelo de la participación de los cristales de colesterol en el desarrollo de EHNA y fibrosis. 1) Cristalización de colesterol en hepatocitos, activación del inflamasoma NLRP3 y producción de quimiocinas y citocinas. 2) Formación de estructuras tipo corona (ETC) a través de la agregación de células de Kupffer (CKs). 3) Transformación de las CKs a células espumosas activadas por acumulación de cristales de colesterol. 4) Activación y transformación de células estelares hepáticas a miofibroblastos productores de colágena. Abreviaturas: IL-1B, interleucina 1 beta; IL18, Interleucina 18; MCP1, proteína quimioatrayente de monocitos 1; TGF-B, factor de crecimiento transformante beta; NLRP3, inflamasoma que contiene los dominios: LRR (rico en repeticiones de leucina), NOD (domino central de unión a nucleótidos NACHT) y un dominio N-terminal PYD (dominios pirina). Basado en 12,130

fatty liver disease. Hepatol. Baltim.Md.41(6): 1313-1321(2005). DOI:10.1002/hep.20701.

5. Chalasani, N., Younossi, Z., Lavine, J.E., Diehl, A.M., Brunt, E.M., Cusi, K., Charlton, M. \& Sanyal, A.J. The diagnosis and management of non-alcoholic fatty liver disease: Practice Guideline by the American Association for the Study of Liver Diseases, American College of Gastroenterology, and the American Gastroenterological Association. Hepatology. 55(6): 2005-2023 (2012). DOI:10.1002/hep. 25762.

6. Sharma, M., Mitnala, S., Vishnubhotla, R.K., Mukherjee, R., Reddy, D.N. \& Rao, P.N. The Riddle of Nonalcoholic Fatty Liver Disease: Progression From Nonalcoholic Fatty Liver to Nonalcoholic Steatohepatitis. J. Clin. Exp. Hepatol. 5(2):147-158 (2015). DOI:10.1016/j.jceh.2015.02.002.

7. Speliotes, E.K., Butler, J.L., Palmer, C.D. \& Voight, B.F. GIANT Consortium, MIGen Consortium, NASH CRN, Hirschhorn JN. PNPLA3 variants specifically confer increased risk for histologic nonalcoholic fatty liver disease but not metabolic disease. Hepatol. Baltim. Md. 52(3):904-912 (2010). DOI:10.1002/hep.23768.
8. Lonardo, A., Byrne, C.D., Caldwell, S.H., Cortez-Pinto, H. \& Targher, G. Global epidemiology of non-alcoholic fatty liver disease. Meta-analytic assessment of prevalence, incidence and outcomes. Hepatology. Mar31.(2016). DOI: 10.1002/hep.28584.

9. Williams, C.D., Stengel, J., Asike, M.I., Torres, D.M., Shaw, J., Contreras, M., Landt, C.L. \& Harrison, S.A. Prevalence of nonalcoholic fatty liver disease and nonalcoholic steatohepatitis among a largely middle-aged population utilizing ultrasound and liver biopsy: a prospective study. Gastroenterology 140(1):124131 (2011). DOI:10.1053/j.gastro.2010.09.038.

10. Charlton, M.R., Burns, J.M., Pedersen, R.A., Watt, K.D., Heimbach, J.K. \& Dierkhising, R.A. Frequency and outcomes of liver transplantation for nonalcoholic steatohepatitis in the United States. Gastroenterology 141(4):1249-1253 (2011). DOI:10.1053/j.gastro.2011.06.061.

11. Wong, R.J., Aguilar, M., Cheung, R., Perumpail, R.B., Harrison, S.A., Younossi, Z.M. \& Ahmed, A. Nonalcoholic steatohepatitis is the second leading etiology of liver disease among adults awaiting liver transplantation in the United States. Gastroenterology 
148(3):547-555 (2015). DOI:10.1053/j.gastro.2014.11.039.

12. Ioannou, G.N. The Role of Cholesterol in the Pathogenesis of NASH. Trends Endocrinol. Metab. TEM. 27(2):84-95 (2016). DOI:10.1016/j.tem.2015.11.008.

13. Day, C.P. \& James, O.F. Steatohepatitis: a tale of two "hits"? Gastroenterology 114(4):842-845 (1998).

14. Neuschwander-Tetri, B.A. Hepatic lipotoxicity and the pathogenesis of nonalcoholic steatohepatitis: the central role of nontriglyceride fatty acid metabolites. Hepatol. Baltim. Md. 52(2):774-788 (2010). DOI:10.1002/hep.23719.

15. Browning, J.D. \& Horton, J.D. Molecular mediators of hepatic steatosis and liver injury. J. Clin. Invest. 114(2):147-152 (2004). DOI:10.1172/JCI22422.

16. Yamaguchi, K., Yang, L., McCall, S., Huang, J., Yu, X.X., Pandey, S.K., Bhanot, S., Monia, B.P., Li, Y.-X. \& Diehl, A.M. Inhibiting triglyceride synthesis improves hepatic steatosis but exacerbates liver damage and fibrosis in obese mice with nonalcoholic steatohepatitis. Hepatol. Baltim. Md. 45(6):1366-1374 (2007). DOI:10.1002/hep.21655.

17. Peretti, N., Sassolas, A., Roy, C.C., Deslandres, C., Charcosset, M., Castagnetti, J., Pugnet-Chardon, L., Moulin, P., Labarge, S., Bouthillier, L., Lachaux, A. \& Levy, E. Department of NutritionHepatogastroenterology, Hôpital Femme Mère Enfant, Bron, Université Lyon 1, Department of Pediatrics, CHU Sainte-Justine Research Center, Université de Montréal. Guidelines for the diagnosis and management of chylomicron retention disease based on a review of the literature and the experience of two centers. Orphanet. J. Rare Dis. 5:24(2010). DOI:10.1186/1750-1172-5-24.

18. Caballero, F., Fernández, A., De Lacy, A.M., Fernández-Checa, J.C., Caballería, J. \& García-Ruiz, C. Enhanced free cholesterol, SREBP-2 and StAR expression in human NASH. J. Hepatol. 50(4):789-796 (2009). DOI:10.1016/j.jhep.2008.12.016.

19. Puri, P., Baillie, R.A., Wiest, M.M., Mirshahi, F., Choudhury, J., Cheung, O., Sargeant C., Contos, M.J. \& Sanyal, A.J. A lipidomic analysis of nonalcoholic fatty liver disease. Hepatol. Baltim. Md. 46(4):1081-1090 (2007). DOI:10.1002/hep.21763.

20. Maldonado Saavedra, O., Ramírez Sánchez, I., García-Sánchez, J.R., Ceballos-Reyes, G.M. \& Méndez-Bolaina, E. Colesterol: Función biológica e implicaciones médicas. Rev. Mex. Cienc. Farm. 43(2):7-22 (2012).

21. Krause, M.R. \& Regen, S.L. The structural role of cholesterol in cell membranes: from condensed bilayers to lipid rafts. Acc. Chem. Res. 47(12):3512-3521 (2014). DOI:10.1021/ar500260t.

22. Ikonen,E.Cellularcholesterol traffickingand compartmentalization. Nat. Rev. Mol. Cell Biol. 9(2):125-138 (2008). DOI:10.1038/ nrm2336.

23. Grundy, S.M. Absorption and metabolism of dietary cholesterol. Annu. Rev. Nutr. 3:71-96 (1983). DOI:10.1146/annurev. nu.03.070183.000443.

24. Berg, J.M., Tymoczko, J.L. \& Stryer, L. Cholesterol is Synthesized from Acetyl Coenzyme A in Three Stages. (2002). http://www. ncbi.nlm.nih.gov/books/NBK22350/. Accessed July 7, 2016.

25. Brown, M.S. \& Goldstein, J.L. The SREBP pathway: regulation of cholesterol metabolism by proteolysis of a membrane-bound transcription factor. Cell 89(3):331-340 (1997)

26. Brown, M.S. \& Goldstein, J.L. A receptor-mediated pathway for cholesterol homeostasis. Science 232(4746):34-47 (1986).

27. Radhakrishnan, A., Goldstein, J.L., McDonald, J.G. \& Brown, M.S. Switch-like control of SREBP-2 transport triggered by small changes in ER cholesterol: a delicate balance. Cell Metab. 8(6):512-521 (2008). DOI:10.1016/j.cmet.2008.10.008.

28. Van Rooyen, D.M., Larter, C.Z., Haigh, W.G., Yeh, M.M., Ioannou, G., Kuver, R., Lee, S.P., Teoh, N.C. \& Farrell, G.C. Hepatic free cholesterol accumulates in obese, diabetic mice and causes nonalcoholic steatohepatitis. Gastroenterology 141(4): 1393-1403 (2011).e1-e5. DOI:10.1053/j.gastro.2011.06.040.

29. Min, H.-K., Kapoor, A., Fuchs, M., Mirshahi, F., Zhou, H., Maher, J., Kellum, J., Warnick, R., Contos, M.J. \& Sanyal, A.J. Increased hepatic synthesis and dysregulation of cholesterol metabolism is associated with the severity of nonalcoholic fatty liver disease. Cell Metab. 15(5):665-674(2012). DOI:10.1016/j.cmet.2012.04.004.

30. Enjoji, M., Yasutake, K., Kohjima, M. \& Nakamuta, M. Nutrition and nonalcoholic Fatty liver disease: the significance of cholesterol. Int. J. Hepatol. 2012:925807 (2012). DOI:10.1155/2012/925807.

31. Papandreou, D., Karabouta, Z.\& Rousso, I. Are dietary cholesterol intake and serum cholesterol levels related to nonalcoholic Fatty liver disease in obese children? Cholesterol 2012:572820 (2012). DOI:10.1155/2012/572820.

32. Zelber-Sagi, S., Ratziu, V. \& Oren, R. Nutrition and physical activity in NAFLD: an overview of the epidemiological evidence. WorldJ. Gastroenterol.17(29):3377-3389(2011). DOI:10.3748/ wjg.v17.i29.3377.

33. Kainuma, M., Fujimoto, M., Sekiya, N., Tsuneyama, K., Cheng, C., Takano, Y., Terasawa, K. \& Shimada, Y. Cholesterol-fed rabbit as a unique model of nonalcoholic, nonobese, non-insulin-resistant fatty liver disease with characteristic fibrosis. J. Gastroenterol. 41(10):971-980 (2006). DOI:10.1007/s00535-006-1883-1.

34. Matsuzawa, N., Takamura, T., Kurita, S., Misu, H., Ota, T., Ando, H., Yokoyama, M., Honda, M., Zen, Y., Nakanuma, Y., Miyamoto, K.-I. \& Kaneko, S. Lipid-induced oxidative stress causes steatohepatitis in mice fed an atherogenic diet. Hepatol. Baltim. Md. 46(5):1392-1403 (2007). DOI:10.1002/hep.21874.

35. Wouters, K., van Gorp, P.J., Bieghs, V., Gijbels, M.J., Duimel, H., Lütjohann, D., Kerksiek, A., van Kruchten, R., Maeda, N., Staels, B., van Bilsen, M., Shiri-Sverdlov, R. \& Hofker, M.H. Dietary cholesterol, rather than liver steatosis, leads to hepatic inflammation in hyperlipidemic mouse models of nonalcoholic steatohepatitis. Hepatol. Baltim. Md. 48(2):474-486 (2008). DOI:10.1002/hep.22363.

36. Ioannou, G.N., Morrow, O.B., Connole, M.L. \& Lee, S.P. Association between dietary nutrient composition and the incidence of cirrhosis or liver cancer in the united states population. Hepatology 50(1):175-184 (2009). DOI:10.1002/hep.22941.

37. Musso, G., Gambino, R., De Michieli, F., Cassader, M., Rizzetto, M., Durazzo, M., Fagà, E., Silli, B. \& Pagano, G. Dietary habits and their relations to insulin resistance and postprandial lipemia in nonalcoholic steatohepatitis. Hepatol. Baltim. Md. 37(4):909916 (2003). DOI:10.1053/jhep.2003.50132. 
38. Yasutake, K., Nakamuta, M., Shima, Y., Ohyama, A., Masuda, K., Haruta, N., Fujino, T., Aoyagi, Y., Fukuizumi, K., Yoshimoto, T., Takemoto, R., Miyahara, T., Harada, N., Hayata, F., Nakashima, M. \& Enjoji, M. Nutritional investigation of non-obese patients with non-alcoholic fatty liver disease: the significance of dietary cholesterol. Scand. J. Gastroenterol. 44(4):471-477 (2009). DOI:10.1080/00365520802588133.

39. Yasutake, K., Kohjima, M., Kotoh, K., Nakashima, M., Nakamuta, M. \& Enjoji, M. Dietary habits and behaviors associated with nonalcoholic fatty liver disease. World J. Gastroenterol. 20(7):1756-1767 (2014). DOI:10.3748/wjg.v20.i7.1756.

40. Musso, G., Cassader, M., Bo, S., De Michieli, F. \& Gambino, R. Sterol regulatory element-binding factor 2 (SREBF-2) predicts 7 -year NAFLD incidence and severity of liver disease and lipoprotein and glucose dysmetabolism. Diabetes 62(4):11091120 (2013). DOI:10.2337/db12-0858.

41. Wang, Y., Tong, J., Chang, B., Wang, B.-F., Zhang, D. \& Wang, B.-Y. Relationship of SREBP-2 rs2228314 G>C polymorphism with nonalcoholic fatty liver disease in a Han Chinese population. Genet. Test Mol. Biomark. 18(9):653-657 (2014). DOI:10.1089/ gtmb.2014.0116.

42. Chalasani, N., Guo, X., Loomba, R., Goodarzi, M.O., Haritunians, T., Kwon, S., Cui, J., Taylor, K.D., Wilson, L., Cummings, O.W., Chen, Y.-D.I. \& Rotter, J.I. Nonalcoholic Steatohepatitis Clinical Research Network. Genome-wide association study identifies variants associated with histologic features of nonalcoholic Fatty liver disease. Gastroenterology 139(5):1567-1576, 1576 (2010). e1-e6. DOI:10.1053/j.gastro.2010.07.057.

43. Bernstein, D.L., Hülkova, H., Bialer, M.G. \& Desnick, R.J. Cholesteryl ester storage disease: Review of the findings in 135 reported patients with an underdiagnosed disease. J. Hepatol. 58(6):1230-1243 (2013). DOI:10.1016/j.jhep.2013.02.014.

44. Burton, B.K., Deegan, P.B., Enns, G.M., Guardamagna, O., Horslen, S., Hovingh, G.K., Lobritto, S.J., Malinova, V., McLin, V.A., Raiman, J., Di Rocco, M., Santra, S., Sharma, R., SykutCegielska, J., Whitley, C.B., Eckert, S., Valayannopoulos, V. \& Quinn, A.G. Clinical Features of Lysosomal Acid Lipase Deficiency.J. Pediatr. Gastroenterol. Nutr. 61(6):619-625(2015). DOI:10.1097/MPG.0000000000000935.

45. Burton, B.K., Balwani, M., Feillet, F., Barić, I., Burrow, T.A., Camarena Grande, C., Coker, M., Consuelo-Sánchez, A., Deegan, P., Di Rocco, M., Enns, G.M., Erbe, R., Ezgu, F., Ficicioglu, C., Furuya, K.N., Kane, J., Laukaitis, C., Mengel, E., Neilan, E.G., Nightingale, S., Peters, H., Scarpa, M., Schwab, K.O., Smolka, V., Valayannopoulos, V., Wood, M., Goodman, Z., Yang, Y., Eckert, S., Rojas-Caro, S. \& Quinn, A.G. A Phase 3 Trial of Sebelipase Alfa in Lysosomal Acid Lipase Deficiency. N. Engl. J. Med. 373(11):1010-1020 (2015). DOI:10.1056/NEJMoa1501365.

46. Sharpe, L.J. \& Brown, A.J. Controlling cholesterol synthesis beyond 3-hydroxy-3-methylglutaryl-CoA reductase (HMGCR). J. Biol. Chem. 288(26):18707-18715 (2013). DOI:10.1074/jbc. R113.479808.

47. Brundert, M., Heeren, J., Merkel, M., Carambia, A., Herkel, J., Groitl, P., Dobner, T., Ramakrishnan, R., Moore, K.J. \&
Rinninger, F. Scavenger receptor CD36 mediates uptake of high density lipoproteins in mice and by cultured cells. J. Lipid. Res. 52(4):745-758 (2011). DOI:10.1194/jlr.M011981.

48. Acton, S., Rigotti, A., Landschulz, K.T., Xu, S., Hobbs, H.H. \& Krieger, M. Identification of scavenger receptor SR-BI as a high density lipoprotein receptor. Science 71(5248):518-520 (1996).

49. Zhao, L., Chen, Y., Tang, R., Chen, Y., Li, Q., Gong, J., Huang, A., Varghese, Z., Moorhead, J.F. \& Ruan, X.Z. Inflammatory stress exacerbates hepatic cholesterol accumulation via increasing cholesterol uptake and de novo synthesis. J. Gastroenterol. Hepatol. 26(5):875-883 (2011). DOI:10.1111/j.1440-1746.2010.06560.x.

50. Miquilena-Colina, M.E., Lima-Cabello, E., Sánchez-Campos, S., García-Mediavilla, M.V., Fernández-Bermejo, M., LozanoRodríguez, T., Vargas-Castrillón, J., Buqué, X., Ochoa, B., Aspichueta, P., González-Gallego, J. \& García-Monzón, C. Hepatic fatty acid translocase CD36 upregulation is associated with insulin resistance, hyperinsulinaemia and increased steatosis in non-alcoholic steatohepatitis and chronic hepatitis C. Gut. 60(10):1394-1402 (2011). DOI:10.1136/gut.2010.222844.

51. Zhou, J., Febbraio, M., Wada, T., Zhai, Y., Kuruba, R., He, J., Lee, J.H., Khadem, S., Ren, S., Li, S., Silverstein, R.L. \& Xie, W. Hepatic fatty acid transporter Cd36 is a common target of LXR, PXR, and PPARgamma in promoting steatosis. Gastroenterology 134(2):556-567 (2008). DOI:10.1053/j.gastro.2007.11.037.

52. Qiu, Y., Liu, S., Chen, H.-T., Yu, C.-H., Teng, X.-D., Yao, H.-T. $\&$ Xu, G.-Q. Upregulation of caveolin-1 and SR-B1 in mice with non-alcoholic fatty liver disease. Hepatobiliary Pancreat. Dis. Int. HBPD INT. 12(6):630-636 (2013).

53. Tomita, K., Teratani, T., Suzuki, T., Shimizu, M., Sato, H., Narimatsu, K., Okada, Y., Kurihara, C., Irie, R., Yokoyama, H., Shimamura, K., Usui, S, Ebinuma, H., Saito, H., Watanabe, C., Komoto, S., Kawaguchi, A., Nagao, S., Sugiyama, K., Hokari, R., Kanai, T., Miura, S. \& Hibi, T. Free cholesterol accumulation in hepatic stellate cells: mechanism of liver fibrosis aggravation in nonalcoholic steatohepatitis in mice. Hepatol. Baltim. Md. 59(1):154-169 (2014). DOI:10.1002/hep.26604.

54. Li,T. \& Chiang, J.Y.L. Regulation of Bile Acid and Cholesterol Metabolism by PPARs. PPAR Res. 2009;2009. DOI:10.1155/2009/501739.

55. Baker, A.D., Malur, A., Barna, B.P., Kavuru, M.S., Malur, A.G. \& Thomassen, M.J. PPARgamma regulates the expression of cholesterol metabolism genes in alveolar macrophages. Biochem. Biophys. Res. Commun. 393(4):682-687 (2010). DOI:10.1016/j. bbrc.2010.02.056.

56. Ricote, M. \& Glass, C.K. New roles for PPARs in cholesterol homeostasis. Trends Pharmacol. Sci. 22(9):441-443; discussion 444 (2001).

57. Ma, K.L., Ruan, X.Z., Powis, S.H., Chen, Y., Moorhead, J.F. \& Varghese, Z. Inflammatory stress exacerbates lipid accumulation in hepatic cells and fatty livers of apolipoprotein E knockout mice. Hepatol. Baltim. Md. 48(3):770-781 (2008). DOI:10.1002/ hep.22423.

58. Montagner, A., Polizzi, A., Fouché, E., Ducheix, S., Lippi, Y., Lasserre, F., Barquissau, V., Régnier, M., Lukowicz, C., 
Benhamed, F., Iroz, A., Bertrand-Michel, J., Al Saati, T., Cano, P., Mselli-Lakhal, L., Mithieux, G., Rajas, F., Lagarrigue, S., Pineau, T., Loiseau, N., Postic, C., Langin, D., Wahli, W. \& Guillou, H. Liver PPAR $\alpha$ is crucial for whole-body fatty acid homeostasis and is protective against NAFLD. Gut. 65(7):1202-1214 (2016). DOI:10.1136/gutjnl-2015-310798.

59. Francque, S., Verrijken, A., Caron, S., Prawitt, J., Paumelle, R., Derudas, B., Lefebvre, P., Taskinen, M.-R., Van Hul, W., Mertens, I., Hubens, G., Van Marck, E., Michielsen, P., Van Gaal, L. \& Staels, B. PPAR $\alpha$ gene expression correlates with severity and histological treatment response in patients with non-alcoholic steatohepatitis. J. Hepatol. 63(1):164-173 (2015). DOI:10.1016/j. jhep.2015.02.019.

60. Arguello, G., Balboa, E., Arrese, M. \& Zanlungo, S. Recent insights on the role of cholesterol in non-alcoholic fatty liver disease. Biochim. Biophys. Acta 1852(9):1765-1778 (2015). DOI:10.1016/j.bbadis.2015.05.015.

61. Musso, G., Gambino, R. \& Cassader, M. Cholesterol metabolism and the pathogenesis of non-alcoholic steatohepatitis. Prog. Lipid Res. 52(1):175-191 (2013). DOI:10.1016/j.plipres.2012.11.002.

62. Fielding, C.J. \& Fielding, P.E. Caveolae and intracellular trafficking of cholesterol. Adv. Drug Deliv. Rev. 49(3):251-264 (2001).

63. Mastrodonato, M., Calamita, G., Rossi, R., Mentino, D., Bonfrate, L., Portincasa, P., Ferri, D. \& Liquori, G.E. Altered distribution of caveolin-1 in early liver steatosis. Eur. J. Clin. Invest. 41(6):642651 (2011). DOI:10.1111/j.1365-2362.2010.02459.x.

64. Carstea, E.D., Morris, J.A., Coleman, K.G., Loftus, S.K., Zhang, D., Cummings, C., Gu, J., Rosenfeld, M.A., Pavan, W.J., Krizman, D.B., Nagle, J., Polymeropoulos, M.H., Sturley, S.L., Ioannou, Y.A., Higgins, M.E., Comly, M., Cooney, A., Brown, A., Kaneski, C.R., Blanchette-Mackie, E.J., Dwyer, N.K., Neufeld, E.B., Chang, T.Y., Liscum, L., Strauss, J.F., Ohno, K., Zeigler, M., Carmi, R., Sokol, J., Markie, D., O’Neill, R.R., van Diggelen, O.P., Elleder, M., Patterson, M.C., Brady, R.O., Vanier, M.T., Pentchev, P.G. \& Tagle, D.A. Niemann-Pick C1 disease gene: homology to mediators of cholesterol homeostasis. Science 277(5323):228-231 (1997).

65. Klein, A.D., Álvarez, A. \& Zanlungo, S. The unique case of the Niemann-Pick type $\mathrm{C}$ cholesterol storage disorder. Pediatr. Endocrinol. Rev. PER. 12 Suppl. 1:166-175 (2014).

66. Carstea, E.D., Polymeropoulos, M.H., Parker, C.C., DeteraWadleigh, S.D., O’Neill, R.R., Patterson, M.C., Goldin, E., Xiao, H., Straub, R.E. \& Vanier, M.T. Linkage of Niemann-Pick disease type $\mathrm{C}$ to human chromosome 18. Proc. Natl. Acad. Sci. U.S.A. 90(5):2002-2004 (1993).

67. Vanier, M.T. Complex lipid trafficking in Niemann-Pick disease type C.J. Inherit. Metab.Dis.38(1):187-199(2015). DOI:10.1007/ s10545-014-9794-4.

68. Jelinek, D., Millward, V., Birdi, A., Trouard, T.P., Heidenreich, R.A. \& Garver, W.S. Npc1 haploinsufficiency promotes weight gain and metabolic features associated with insulin resistance. Hum. Mol. Genet. 20(2):312-321 (2011). DOI:10.1093/hmg/ ddq466.
69. Soccio, R.E. \& Breslow, J.L. StAR-related lipid transfer(START) proteins: mediators of intracellular lipid metabolism.J. Biol. Chem. 278(25):22183-22186 (2003). DOI:10.1074/jbc.R300003200.

70. Stocco, D.M. The role of the StAR protein in steroidogenesis: challenges for the future. J. Endocrinol. 164(3):247-253 (2000).

71. Charman, M., Kennedy, B.E., Osborne, N. \& Karten, B.. MLN64 mediates egress of cholesterol from endosomes to mitochondria in the absence of functional Niemann-Pick Type C1 protein. $J$. Lipid Res. 51(5):1023-1034 (2010). DOI:10.1194/jlr.M002345.

72. Tichauer, J.-E., Morales., M.-G., Amigo, L., Galdames, L., Klein, A., Quinones, V., Ferrada, C., Álvarez, A.-R., Río, M.-C., Miquel, J.-F., Rigotti, A. \& Zanlungo, S. Overexpression of the cholesterol-binding protein MLN64 induces liver damage in the mouse. World J. Gastroenterol. 13(22):3071-3079 (2007).

73. Olkkonen, V.M. OSBP-related proteins: liganding by glycerophospholipids opens new insight into their function. Mol. Basel. Switz. 18(11):13666-13679 (2013). DOI:10.3390/ molecules181113666.

74. Zhou, T., Li, S., Zhong, W., Vihervaara, T., Béaslas, O., Perttilä, J., Luo, W., Jiang, Y., Lehto, M., Olkkonen, V.M. \& Yan, D. OSBP-related protein 8 (ORP8) regulates plasma and liver tissue lipid levels and interacts with the nucleoporin Nup62. PloS One. 6(6):e21078 (2011). DOI:10.1371/journal.pone.0021078.

75. Joyce, C., Freeman, L., Brewer, H.B. \& Santamarina-Fojo, S. Study of ABCA1 function in transgenic mice. Arterioscler. Thromb. Vasc. Biol. 23(6):965-971 (2003). DOI:10.1161/01. ATV.0000055194.85073.FF.

76. Liu, W., Qin, L., Yu, H., Lv, F. \& Wang, Y. Apolipoprotein A-I and adenosine triphosphate-binding cassette transporter A1 expression alleviates lipid accumulation in hepatocytes. J. Gastroenterol. Hepatol. 29(3):614-622 (2014). DOI: 10.1111/jgh.12430.

77. Yang, Y., Jiang, Y., Wang, Y. \& An, W. Suppression of ABCA1 by unsaturated fatty acids leads to lipid accumulation in HepG2 cells. Biochimie. 2010;92(8):958-963 (2013). DOI:10.1016/j. biochi.2010.04.002.

78. Vega-Badillo, J., Gutiérrez-Vidal, R., Hernández-Pérez, H.A., Villamil-Ramírez, H., León-Mimila, P., Sánchez-Muñoz, F., Morán-Ramos, S., Larrieta-Carrasco, E., Fernández-Silva, I., Méndez-Sánchez, N., Tovar, A.R., Campos-Pérez, F., VillarrealMolina, T., Hernández-Pando, R., Aguilar-Salinas, C.A. \& Canizales-Quinteros, S. Hepatic miR-33a/miR-144 and their target gene ABCA1 are associated with steatohepatitis in morbidly obese subjects. Liver Int. 36(9):1383-1391 (2016). DOI:10.1111/ liv.13109.

79. Kennedy, M.A., Barrera, G.C., Nakamura, K., Baldán, A., Tarr, P., Fishbein, M.C., Frank, J., Francone, O.L. \& Edwards, P.A. ABCG1 has a critical role in mediating cholesterol efflux to HDL and preventing cellular lipid accumulation. Cell Metab. 1(2):121131 (2005). DOI:10.1016/j.cmet.2005.01.002.

80. Terasaka, N., Wang, N., Yvan-Charvet, L. \& Tall, A.R. Highdensity lipoprotein protects macrophages from oxidized lowdensity lipoprotein-induced apoptosis by promoting efflux of 7-ketocholesterol via ABCG1. Proc. Natl. Acad. Sci. U.S.A. 104(38):15093-15098 (2007). DOI:10.1073/pnas.0704602104. 
81. Yu, L., Gupta, S., Xu, F., Liverman, A.D.B, Moschetta, A., Mangelsdorf, D.J., Repa, J.J., Hobbs, H.H. \& Cohen, J.C. Expression of ABCG5 and ABCG8 is required for regulation of biliary cholesterol secretion. J. Biol. Chem. 280(10):8742-8747 (2005). DOI:10.1074/jbc.M411080200.

82. Su, K., Sabeva, N.S., Liu, J., Wang, Y., Bhatnagar, S., van der Westhuyzen, D.R. \& Graf, G.A. The ABCG5 ABCG8 sterol transporter opposes the development of fatty liver disease and loss of glycemic control independently of phytosterol accumulation. J. Biol. Chem. 287(34):28564-28575 (2012). DOI:10.1074/jbc. M112.360081.

83. Spolding, B., Connor, T., Wittmer, C., Abreu, L.L.F., Kaspi, A., Ziemann, M., Kaur, G., Cooper, A., Morrison, S., Lee, S., Sinclair, A., Gibert, Y., Trevaskis J.L., Roth, J.D., El-Osta, A., Standish, R. \& Walder, K. Rapid development of non-alcoholic steatohepatitis in Psammomys obesus (Israeli sand rat). PloS One 9(3):e92656 (2014). DOI:10.1371/journal.pone.0092656.

84. Savard, C., Tartaglione, E.V., Kuver, R., Haigh, W.G., Farrell G.C., Subramanian, S., Chait, A., Yeh, M.M., Quinn, L.S. \&Ioannou, G.N. Synergistic interaction of dietary cholesterol and dietary fat in inducing experimental steatohepatitis. Hepatology 57(1):81-92 (2013). DOI:10.1002/hep.25789.

85. Bartel, D.P. MicroRNAs: target recognition and regulatory functions. Cell136(2):215-233 (2009). DOI:10.1016/j. cell.2009.01.002.

86. Zamore, P.D. \& Haley, B. Ribo-gnome: the big world of small RNAs. Science 309(5740):1519-1524 (2005). DOI:10.1126/ science. 1111444.

87. Ambros, V. MicroRNAs and developmental timing. Curr. Opin. Genet. Dev. 21(4):511-517. (2011). DOI:10.1016/j. gde.2011.04.003.

88. Ceccarelli, S., Panera, N., Gnani, D. \& Nobili, V. Dual role of microRNAs in NAFLD. Int. J. Mol Sci. 14(4):8437-8455 (2013). DOI:10.3390/ijms14048437.

89. Cheung, O., Puri, P., Eicken, C., Contos, M.J., Mirshahi, F., Maher, J.W., Kellum, J.M., Min H., Luketic, V.A. \& Sanyal, A.J. Nonalcoholic steatohepatitis is associated with altered hepatic MicroRNA expression. Hepatol. Baltim. Md. 48(6):1810-1820 (2008). DOI:10.1002/hep.22569.

90. Jin, X., Ye, Y.-F., Chen, S.-H., Yu, C.-H., Liu, J. \& Li, Y.-M. MicroRNA expression pattern in different stages of nonalcoholic fatty liver disease. Dig. Liver. Dis. Off J. Ital. Soc. Gastroenterol. Ital. Assoc. Study. Liver. 41(4):289-297 (2009). DOI:10.1016/j. dld.2008.08.008.

91. Vincent, R. \& Sanyal, A. Recent Advances in Understanding of NASH: MicroRNAs as Both Biochemical Markers and Players. Curr. Pathobiol. Rep. 2(3):109-115(2014). DOI:10.1007/s40139014-0049-8.

92. Braza-Boïls, A., Marí-Alexandre, J., Molina, P., Arnau, M.A., Barceló-Molina, M., Domingo, D., Girbes, J., Giner, J., MartínezDolz, L. \& Zorio, E. Deregulated hepatic microRNAs underlie the association between non-alcoholic fatty liver disease and coronary artery disease. Liver Int.36(8):1221-1229. (2016). DOI: 10.1111/ liv.13097.
93. Lagos-Quintana, M., Rauhut, R., Yalcin, A., Meyer, J., Lendeckel, W.\& Tuschl, T. Identification of tissue-specific microRNAs from mouse. Curr. Biol. CB. 12(9):735-739 (2002).

94. Chang, J., Nicolas, E., Marks, D., Sander, C., Lerro, A., Buendía, M.A., Xu, C., Mason, W.S., Moloshok T., Bort, R., Zaret, K.S. \& Taylor, J.M. miR-122, a mammalian liver-specific microRNA, is processed from hor mRNA and may downregulate the high affinity cationic amino acid transporter CAT-1. RNA Biol. 1(2):106-113 (2004).

95. Esau, C., Davis, S., Murray, S.F., Yu, X.X., Pandey, S.K., Pear, M, Watts, L., Booten, S.L., Graham, M., McKay, R., Subramaniam, A., Propp, S., Lollo, B.A., Freier, S., Bennett, C.F., Bhanot, S. \& Monia, B.P. miR-122 regulation of lipid metabolism revealed by in vivo antisense targeting. Cell Metab. ;3(2):87-98 (2006). DOI:10.1016/j.cmet.2006.01.005.

96. Song, K.-H., Li, T., Owsley, E. \& Chiang, J.Y.L. A putative role of micro RNA in regulation of cholesterol 7alpha-hydroxylase expression in human hepatocytes. J. Lipid. Res. 51(8):2223-2233 (2010). DOI:10.1194/j1r.M004531.

97. Krützfeldt, J., Rajewsky, N., Braich, R., Rajeev, K.G., Tuschl, T., Manoharan, M. \& Stoffel, M. Silencing of microRNAs in vivo with “antagomirs." Nature 438(7068):685-689 (2005). DOI:10.1038/ nature 04303.

98. Li, S., Chen, X., Zhang, H., Liang, X., Xiang, Y., Yu, C., Zen, K., Li, Y. \& Zhang, C.-Y. Differential expression of microRNAs in mouse liver under aberrant energy metabolic status. J. Lipid Res. 50(9):1756-1765 (2009). DOI:10.1194/jlr.M800509-JLR200.

99. Sun, C., Huang, F., Liu, X., Xiao, X., Yang, M., Hu, G., Liu, H. \& Liao, L. miR-21 regulates triglyceride and cholesterol metabolism in non-alcoholic fatty liver disease by targeting HMGCR. Int. J. Mol.Med.35(3):847-853(2015). DOI:10.3892/ijmm.2015.2076.

100. Gerin, I., Clerbaux, L.-A., Haumont, O., Lanthier, N., Das, A.K., Burant, C.F., Leclercq, I.A., MacDougald, O.A. \& Bommer, G.T. Expression of miR-33 from an SREBP2 intron inhibits cholesterol export and fatty acid oxidation. J. Biol. Chem. 285(44):3365233661 (2010). DOI:10.1074/jbc.M110.152090.

101. Rayner, K.J., Suárez, Y., Dávalos, A., Parathath, S., Fitzgerald, M.L., Tamehiro, N., Fisher, E.A., Moore, K.J. \& FernándezHernando, C. MiR-33 contributes to the regulation of cholesterol homeostasis. Science 328(5985): 1570-1573 (2010). DOI:10.1126/science.1189862.

102. Marquart, T.J., Allen, R.M., Ory, D.S. \& Baldán, A. miR-33 links SREBP-2 induction to repression of sterol transporters. Proc. Natl. Acad. Sci. U.S.A. 107(27):12228-12232 (2010). DOI:10.1073/pnas.1005191107.

103. Najafi-Shoushtari, S.H., Kristo, F., Li, Y., Shioda, T., Cohen, D.E., Gerszten, R.E. \& Näär, A.M. MicroRNA-33 and the SREBP host genes cooperate to control cholesterol homeostasis. Science 328(5985): 1566-1569 (2010). DOI:10.1126/science.1189123.

104. Horie, T., Ono, K., Horiguchi, M., Nishi, H., Nakamura, T., Nagao, K., Kinoshita, M., Kuwabara, Y., Marusawa, H., Iwanaga, Y., Hasegawa, K., Yokode, M., Kimura, T. \& Kita, T. MicroRNA-33 encoded by an intron of sterol regulatory element-binding protein 2 (Srebp2) regulates HDL in vivo. Proc. Natl. Acad. Sci. U.S.A. 
107(40):17321-17326 (2010). DOI:10.1073/pnas.1008499107.

105. Rayner, K.J., Esau, C.C., Hussain, F.N., McDaniel,A.L., Marshall, S.M., van Gils, J.M., Ray, T.D., Sheedy, F.J., Goedeke, L., Liu, X., Khatsenko, O.G., Kaimal, V., Lees, C.J., Fernández-Hernando, C., Fisher, E.A., Temel, R.E. \& Moore, K.J. Inhibition of miR-33a/b in non-human primates raises plasma HDL and lowers VLDL triglycerides. Nature 478(7369):404-407 (2011). DOI:10.1038/ nature10486.

106. Lendvai, G., Jármay, K., Karácsony, G., Halász, T., Kovalszky, I., Baghy, K., Wittmann, T., Schaff, Z. \& Kiss, A. Elevated miR-33a and miR-224 in steatotic chronic hepatitis $\mathrm{C}$ liver biopsies. World J. Gastroenterol. 20(41):15343-15350 (2014). DOI:10.3748/wjg.v20.i41.15343.

107. de Aguiar Vallim, T.Q., Tarling, E.J., Kim, T., Civelek, M., Baldán, Á., Esau, C. \& Edwards, P.A. MicroRNA-144 regulates hepatic ATP binding cassette transporter A1 and plasma highdensity lipoprotein after activation of the nuclear receptor farnesoid X receptor. Circ. Res. 112(12):1602-1612 (2013). DOI:10.1161/CIRCRESAHA.112.300648.

108. Ramírez, C.M., Rotllan, N., Vlassov, A.V., Dávalos, A., Li M., Goedeke, L., Aranda, J.F., Cirera-Salinas, D., Araldi, E., Salerno, A., Wanschel, A., Zavadil, J., Castrillo, A., Kim, J., Suárez, Y. \& Fernández-Hernando, C. Control of cholesterol metabolism and plasma high-density lipoprotein levels by microRNA-144. Circ. Res. 112(12):1592-1601 (2013). DOI:10.1161/ CIRCRESAHA.112.300626.

109. Hu, Y.-W., Hu, Y.-R., Zhao, J.-Y., Li, S.-F., Ma, X., Wu, S.G., Lu, J.-B., Qiu, Y.-R., Sha, Y.-H., Wang, Y.-C., Gao, J.-J., Zheng, L. \& Wang, Q. An agomir of miR-144-3p accelerates plaque formation through impairing reverse cholesterol transport and promoting pro-inflammatory cytokine production. PloS One 9(4):e94997 (2014). DOI:10.1371/journal.pone.0094997.

110. Montero, J., Mari, M., Colell, A., Morales, A., Basáñez, G., García-Ruiz, C. \& Fernández-Checa, J.C. Cholesterol and peroxidized cardiolipin in mitochondrial membrane properties, permeabilization and cell death. Biochim. Biophys. Acta 1797(67):1217-1224 (2010). DOI:10.1016/j.bbabio.2010.02.010.

111. García-Ruiz, C., Mari, M., Colell, A., Morales, A., Caballero, F., Montero, J., Terrones, O., Basáñez, G. \& Fernández-Checa, J.C. Mitochondrial cholesterol in health and disease. Histol. Histopathol. 24(1):117-132 (2009).

112. Tabas, I. Consequences of cellular cholesterol accumulation: basic concepts and physiological implications. J. Clin. Invest. 110(7):905-911 (2002). DOI:10.1172/JCI16452.

113. Yeagle, P.L. Modulation of membrane function by cholesterol. Biochimie. 73(10):1303-1310 (1991).

114. Marí, M., Caballero, F., Colell, A., Morales, A., Caballería, J., Fernández, A., Enrich, C., Fernández-Checa, J.C. \& García-Ruiz, C. Mitochondrial free cholesterol loading sensitizes to TNF- and Fas-mediated steatohepatitis. Cell Metab. 4(3):185-198 (2006). DOI:10.1016/j.cmet.2006.07.006.

115. Hager, L., Li, L., Pun, H., Liu, L., Hossain, M.A., Maguire, GF, Naples, M., Baker, C., Magomedova, L., Tam, J., Adeli, K., Cummins, C.L., Connelly, P.W. \& Ng, D.S. Lecithin:cholesterol acyltransferase deficiency protects against cholesterol-induced hepatic endoplasmic reticulum stress in mice. J. Biol. Chem. 287(24):20755-20768 (2012). DOI:10.1074/jbc.M112.340919.

116. Li, L., Hossain, M.A., Sadat, S., Hager, L., Liu, L., Tam, L., Schroer, S., Huogen, L., Fantus, I.G., Connelly, P.W., Woo, M. \& Ng, D.S. Lecithin cholesterol acyltransferase null mice are protected from diet-induced obesity and insulin resistance in a gender-specific manner through multiple pathways. $J$. Biol. Chem. 286(20):17809-17820 (2011). DOI:10.1074/jbc. M110.180893.

117. Gentile, C.L., Frye, M.\& Pagliassotti, M.J.Endoplasmic reticulum stress and the unfolded protein response in nonalcoholic fatty liver disease. Antioxid. Redox Signal. 15(2):505-521 (2011). DOI:10.1089/ars.2010.3790.

118. Fu, S., Yang, L., Li, P., Hofmann, O., Dicker, L., Hide, W., Lin, X., Watkins, S.M., Ivanov, A.R. \& Hotamisligil, G.S. Aberrant lipid metabolism disrupts calcium homeostasis causing liver endoplasmic reticulum stress in obesity. Nature 473(7348):528531 (2011). DOI:10.1038/nature09968.

119. Park, S.W., Zhou, Y., Lee, J., Lee, J. \& Ozcan, U. Sarco(endo) plasmic reticulum $\mathrm{Ca} 2+-\mathrm{ATPase} 2 \mathrm{~b}$ is a major regulator of endoplasmic reticulum stress and glucose homeostasis in obesity. Proc. Natl. Acad. Sci. U.S.A. 107(45):19320-19325 (2010). DOI:10.1073/pnas.1012044107.

120. Leroux, A., Ferrere, G., Godie, V., Cailleux, F., Renoud, M.-L., Gaudin, F., Naveau, S., Prévot, S., Makhzami, S., Perlemuter, G. \& Cassard-Doulcier, A.-M. Toxic lipids stored by Kupffer cells correlates with their pro-inflammatory phenotype at an early stage of steatohepatitis. J. Hepatol. 57(1):141-149 (2012). DOI:10.1016/j.jhep.2012.02.028.

121. Bieghs, V., van Gorp, P.J., Walenbergh, S.M.A., Gijbels, M.J., Verheyen, F., Buurman, W.A., Briles, D.E., Hofker, M.H., Binder, C.J. \& Shiri-Sverdlov, R. Specific immunization strategies against oxidized low-density lipoprotein: a novel way to reduce nonalcoholic steatohepatitis in mice. Hepatol. Baltim. Md. 56(3):894-903 (2012). DOI:10.1002/hep.25660.

122. Hendrikx, T., Bieghs, V., Walenbergh, S.M.A., van Gorp, P.J., Verheyen, F., Jeurissen, M.L.J., Steinbusch, M.M.F., Vaes, N., Binder, C.J., Koek, G.H., Stienstra, R., Netea, M.G., Hofker, M.H. \& Shiri-Sverdlov, R. Macrophage specific caspase-1/11 deficiency protects against cholesterol crystallization and hepatic inflammation in hyperlipidemic mice. PloS One. 8(12): 78792 (2013). DOI:10.1371/journal.pone.0078792.

123. Bieghs, V., Hendrikx, T., van Gorp, P.J., Verheyen, F., Guichot, Y.D., Walenbergh, S.M.A., Jeurissen, M.L.J., Gijbels, M., Rensen, S.S., Bast, A., Plat, J., Kalhan, S.C., Koek, G.H., Leitersdorf, E., Hofker, M.H., Lütjohann, D. \& Shiri-Sverdlov, R. The cholesterol derivative 27-hydroxycholesterol reduces steatohepatitis in mice. Gastroenterology 144(1):167-178.e1 (2013). DOI:10.1053/j.gastro.2012.09.062.

124. Liu, B., Ramírez, C.M., Miller, A.M., Repa, J.J., Turley, S.D. \& Dietschy, J.M. Cyclodextrin overcomes the transport defect in nearly every organ of NPC1 mice leading to excretion of sequestered cholesterol as bile acid. J. Lipid Res. 51(5):933-944 
(2010). DOI:10.1194/jlr.M000257.

125. Fujii, H. \& Kawada, N. Inflammation and fibrogenesis in steatohepatitis. J. Gastroenterol. 47(3):215-225 (2012). DOI:10.1007/s00535-012-0527-x.

126. Teratani, T., Tomita, K., Suzuki, T., Oshikawa, T., Yokoyama, H., Shimamura, K., Tominaga, S., Hiroi, S., Irie, R., Okada, Y., Kurihara, C., Ebinuma, H., Saito, H., Hokari, R., Sugiyama, K., Kanai, T., Miura, S. \& Hibi, T. A high-cholesterol diet exacerbates liver fibrosis in mice via accumulation of free cholesterol in hepatic stellate cells. Gastroenterology 142(1):152-164.e10 (2012). DOI:10.1053/j.gastro.2011.09.049.

127. Tomita, K., Teratani, T., Suzuki, T., Shimizu, M., Sato, H., Narimatsu, K., Usui, S., Furuhashi, H., Kimura, A., Nishiyama, K., Maejima, T., Okada, Y., Kurihara, C., Shimamura, K., Ebinuma, H., Saito, H., Yokoyama, H., Watanabe, C., Komoto, S., Nagao, S., Sugiyama, K., Aosasa, S., Hatsuse, K., Yamamoto, J., Hibi, T., Miura, S., Hokari, R. \& Kanai, T. Acyl-CoA:cholesterol acyltransferase 1 mediates liver fibrosis by regulating free cholesterol accumulation in hepatic stellate cells. J. Hepatol. 61(1):98-106 (2014). DOI:10.1016/j.jhep.2014.03.018.

128. Duewell, P., Kono, H., Rayner, K.J., Sirois, C.M., Vladimer,
G., Bauernfeind, F.G., Abela, G.S., Franchi, L., Núñez, G., Schnurr, M., Espevik, T., Lien, E., Fitzgerald, K.A., Rock, K.L., Moore, K.J., Wright, S.D., Hornung, V. \& Latz, E. NLRP3 inflammasomes are required for atherogenesis and activated by cholesterol crystals. Nature 464(7293):1357-1361 (2010). DOI:10.1038/nature08938.

129. Rajamäki, K., Lappalainen, J., Oörni, K., Välimäki, E., Matikainen, S., Kovanen, P.T. \& Eklund, K.K. Cholesterol crystals activate the NLRP3 inflammasome in human macrophages: a novel link between cholesterol metabolism and inflammation. PloSOne 5(7):e11765 (2010). DOI:10.1371/ journal.pone.0011765.

130. Ioannou, G.N., Haigh, W.G., Thorning, D. \& Savard, C. Hepatic cholesterol crystals and crown-like structures distinguish NASH from simple steatosis. J. Lipid. Res. 54(5):1326-1334 (2013). DOI:10.1194/j1r.M034876.

131. Ioannou, G.N., Van Rooyen, D.M., Savard, C., Haigh, W.G., Ye, M.M., Teoh, N.C. \& Farrell, G.C. Cholesterol-lowering drugs cause dissolution of cholesterol crystals and disperse Kupffer cell crown-like structures during resolution of NASH. J. Lipid. Res. 56(2):277-285 (2015). DOI:10.1194/jlr.M053785. 